\title{
Evaluando al gobierno electrónico: avances en la transparencia de las finanzas públicas estatales
}

\author{
LaURa SOUR-VARgas*
}

\begin{abstract}
The adoption of the electronic government system by the public administration has created a new relationship between the citizenry and the Government. However, in the case of Mexico, the question of whether the electronic government system can actually improve its transparency has still not been answered. Following the literature about the effect of the pressure of globalisation on bureaucratic change, this paper compares the transparency of the figures for public finances found on various State web pages (electronic government) against the information that each State is required to publish according to the Ley de Transparecia y Accesso a la Información Pública - LTAIP (Transparency and access to public information act). In $70 \%$ of the cases the results show that the electronic government on its own cannot affect the transparency of the public finances. In order to change the transparency it is necessary to modify the institutional context and the characteristics of the different organisations.
\end{abstract}

Keywords: electronic government, transparency, State public finances, Mexico.

\section{Resumen}

La adopción del sistema de gobierno electrónico por parte de la administración pública ha creado una nueva relación entre la ciudadanía y el gobierno. Sin embargo, la pregunta de si puede el gobierno electrónico mejorar la transparencia permanece todavía sin ser contestada para el caso de México. De acuerdo con la literatura del efecto de las presiones de la globalización sobre el cambio burocrático, en este trabajo se compara la transparencia de las cifras de finanzas públicas encontradas en las páginas Internet estatales (gobierno electrónico) con lo que, de acuerdo con la Ley de Transparencia y Acceso a la Información Pública (LTAIP), cada estado está obligado a publicar. En $70 \%$ de los casos, los resultados confirman que el gobierno electrónico por sí solo no puede afectar la transparencia de las finanzas públicas. Para cambiar la transparencia es necesario modificar el contexto institucional y las características de las organizaciones.

Palabras clave: gobierno electrónico, transparencia, finanzas públicas estatales, México.

* Centro de Investigación y Docencia Económicas, A.c. (CIDE). Correo-e: laura.sour@cide.edu 


\section{Introducción}

Durante los últimos años, en todo el mundo ha surgido una nueva forma de hacer gobierno, una forma que ha revolucionado la relación entre la ciudadanía y los funcionarios públicos. Dicha forma de gobierno es denominada gobierno electrónico, la cual funciona por medio de las Tecnologías de Información y Comunicación (TIC). El nacimiento del gobierno electrónico prometió que las dependencias gubernamentales ofrecerían sus servicios de una manera más eficiente, mejorando así la administración pública.

El gobierno electrónico es considerado y promocionado en todo el mundo como un promotor de la rendición de cuentas: en la medida que más información es entregada en un tiempo mucho más razonable a los ciudadanos, se espera que aumente la transparencia del gobierno y que se permita a los ciudadanos monitorear más de cerca el desempeño de los funcionarios públicos (La Porte et. al., 2002). Además, la mejora en la interacción que supone el uso de la tecnología facilitará la rendición de cuentas al hacer al gobierno más responsivo a las necesidades y demandas de los individuos (Demchak et al., 2000).

Sin embargo, algunos autores argumentan que el gobierno electrónico sólo mejora la eficiencia técnica de las organizaciones públicas, sin lograr un cambio significativo en su naturaleza. Es decir, el contexto en el cual las TIC son aplicadas constituye una fuerza mucho más influyente que la aplicación de la tecnología misma para generar un cambio en las estructuras organizacionales. Por ejemplo, existe evidencia de que gobiernos cuya naturaleza es autoritaria utilizan la tecnología para controlar el acceso a la información con el propósito de monitorear el comportamiento de los ciudadanos y aumentar así el control político del régimen (Wong y Welch, 1998). Entonces, el papel del gobierno electrónico se reduce a reforzar las "tendencias ya existentes" dentro de las organizaciones (Kraemer y Dedrick, 1997: 101; Agre, 2002).

Aplicando esta lógica al impacto del gobierno electrónico sobre la transparencia, las TIC pueden limitarse a ampliar la naturaleza de las organizaciones, mejorando o reduciendo los niveles de transparencia sólo en la medida en la que el marco institucional o las circunstancias ya existentes así lo permitan. Desde esta perspectiva, la relación entre gobierno electrónico y el cambio en la transparencia está condicionada al contexto y las características 
de las organizaciones públicas. La respuesta a esta relación se encuentra en la literatura que estudia las presiones que la globalización impone a la burocracia local: por ejemplo, la globalización puede presionar a las burocracias locales para generar modificaciones en su comportamiento, como lo es su transparencia. Sin embargo, estas presiones que ejerce la globalización son filtradas por el entorno que rodea a las organizaciones locales. Así, el contexto local puede reforzar, ampliar o cancelar el cambio generado por las fuerzas de la globalización. Wong y Welch (2004) analizan una muestra de 14 países y concluyen que la sola introducción del gobierno electrónico, sin las correspondientes reformas institucionales a las organizaciones y su burocracia, no representa una mejora significativa en la rendición de cuentas de los países.

En el caso específico de México, la implantación de la tecnología para adoptar nuevas formas de gobierno comenzó durante la administración del presidente Ernesto Zedillo, y el boom se presentó con la llegada de Vicente Fox a la presidencia de la República. En suma, desde hace casi cinco años tanto el gobierno federal como los gobiernos estatales se han preocupado por incursionar en la nueva cultural mundial del gobierno electrónico. Por otra parte, la Ley Federal de Acceso a la Información Pública Gubernamental (LTAIP) aprobada en el 2002 incorporó un nuevo marco institucional a la cultura del gobierno electrónico en México cuyo impacto no ha sido igual en las entidades federativas del país. Así, ante la popularidad que ha cobrado el gobierno electrónico y la creciente interacción entre gobierno y ciudadanos a través de la Internet, surge la pregunta: ¿hasta qué punto el gobierno electrónico ha promovido la transparencia en los estados de México ante el cambio en el entorno local que trajo la promulgación de las LTAIP estatales?

Para contestar esta pregunta, en el presente trabajo se hizo un análisis de las agencias estatales que dentro de su misión consideren que la publicación de información es un símbolo de confianza y modernidad. Por ello, se compara el desglose y actualización de las cifras de finanzas públicas divulgadas en los portales de las entidades federativas mexicanas con lo que la Ley de Transparencia y Acceso a la Información Pública (LTAIP) en cada estado señala que deben reportar. ${ }^{1}$

\footnotetext{
${ }^{1}$ Los gobiernos estatales enfrentan diversos retos en su camino hacia la instrumentación exitosa del gobierno electrónico. Por ejemplo, uno de ellos consiste en garantizar el acceso a los servicios electrónicos a la mayoría de la población. Esta problemática se conoce en la literatura como brecha digital, misma que no se aborda por rebasar el objetivo del presente trabajo.
} 
El trabajo está organizado en cuatro secciones. En la primera se presenta una introducción al tema del gobierno electrónico y a su desarrollo e implantación en México y en los estados del país. En la segunda sección se presenta una explicación del concepto de transparencia y del desarrollo y los alcances de su marco normativo en las entidades federativas de México. En la tercera parte se presenta el marco teórico para analizar el efecto del gobierno electrónico sobre la transparencia. En la cuarta sección se evalúa el progreso alcanzado por el gobierno electrónico para mejorar la transparencia de las finanzas estatales en México y fortalecer la rendición de cuentas. Finalmente, se presenta un apartado dedicado a las conclusiones.

\section{Gobierno electrónico}

El gobierno electrónico es una forma de organización que, por medio de las TIC, conforma un ambiente virtual en el cual los ciudadanos y el gobierno pueden interactuar vía Internet. Este tipo de tecnología tiene su antecedente en la industria privada, la cual desarrolló sistemas electrónicos de negocios en aras de mejorar la eficiencia tanto en sus procesos productivos como en sus ventas. Dichos sistemas se denominaron e-business y e-commerce. A partir de éstos surgió como una posibilidad viable sistematizar algunos procesos gubernamentales para beneficio de la sociedad. Las posibilidades que presenta el gobierno electrónico son mucho más diversas y complejas que las de sus antecesores, por ello su implantación requiere de un esfuerzo mayor y la tarea resulta más complicada.

Es necesario establecer una definición clara de lo que es el gobierno electrónico para delimitar sus alcances. En primer lugar, gobierno electrónico no es un simple contacto vía Internet entre el gobierno, la industria y los ciudadanos. Gobierno electrónico debe entenderse como una interacción entre política, gobierno, administración, ciudadanos, industria privada y organizaciones civiles. Así pues, gobierno electrónico "es una forma de organización del Estado que integra las interacciones e interrelaciones entre el Estado y los ciudadanos, industrias privadas, clientes e instituciones públicas a través de la utilización de tecnologías de información y comunicación modernas" (Schedler et al., 2004: 5). ${ }^{2}$

${ }^{2}$ Cabe mencionar que la definición de Schedler enfatiza más el aspecto de las interacciones entre los actores que el aspecto de los procesos para la toma de decisiones de política pública. 
Una pregunta que no podemos dejar de lado es: ¿por qué le puede interesar al Estado instrumentar un sistema de gobierno electrónico? El gobierno tiene como ejemplo los beneficios que obtuvieron las empresas que introdujeron los sistemas de $e$-business, con los que lograron que la comunicación cliente-empresa y empresa-empresa se efectuara de una forma más rápida y barata, y que se redujeran costos y se propiciara el surgimiento de una cultura de atención personal, apertura y respuesta inmediata en el sector privado. Así pues, el gobierno puede trasladar este mecanismo para generar una vía de interacción con la ciudadanía y obtener resultados similares en materia de eficiencia, participación y rendición de cuentas. Sin embargo, "El proceso de diseño, implementación, y mantenimiento de un programa de gobierno electrónico es caro y complejo" (Kossic, 2003a: 11).

El esfuerzo económico que requiere el desarrollo de un sistema de gobierno electrónico es bastante grande, pues los proyectos de ese tipo son difíciles de instrumentar, y requieren de grandes sumas de capital. El adecuado retorno de capital en los proyectos de gobierno electrónico se mide por el nivel de adopción generalizada por parte de la población, su funcionamiento eficiente y por su impacto positivo. El plan del gobierno para establecer este tipo de sistemas debe tener en cuenta que se logre dicho retorno de capital. Aquellos que fallen en este aspecto corren el riesgo de que el diseño de su sistema sea inadecuado o incluso que el proyecto quede inconcluso (Lenihan, 2002).

El proceso del programa de gobierno electrónico es complejo porque requiere la cooperación de cuerpos administrativos para lograr un funcionamiento eficiente. Una de las características principales de los sistemas que utilizan las TIC es la integración. Ello implica que las dependencias gubernamentales no pueden desarrollar sistemas de gobierno electrónico de forma individual. En caso de que alguna lo hiciera o tomara la decisión de no cooperar en la conformación del gobierno electrónico como una sola entidad articulada, más allá de mejorar la eficiencia de los servicios gubernamentales, la perjudicaría (Lenihan, 2002).

Uno de los objetivos principales de los programas de gobierno electrónico es la interacción entre la ciudadanía y el gobierno. Por medio del gobierno electrónico se debe brindar la posibilidad de que los ciudadanos accedan por los portales electrónicos a los servicios públicos que brindan las dependencias gubernamentales. Estas nuevas tecnologías no sólo deben ir encaminadas a agilizar trámites, sino que también habrán de constituirse 
en una "herramienta fundamental de los procesos de transparencia y rendición de cuentas y para el impulso de la calidad en el servicio público" (López, 2003: 28).

Así pues, "con el apoyo de la tecnología, es posible establecer espacios más amplios de participación ciudadana y por lo tanto mayores flujos de demandas hacia las instancias de gobierno" (López, 2003: 28). Un sistema de gobierno electrónico bien articulado y establecido debe propiciar una participación más activa de la ciudadanía en los procesos de toma de decisiones de los representantes políticos. El alcance del gobierno electrónico debe permitir la participación e interacción en todos los niveles de gobierno.

El gobierno electrónico puede incrementar la rendición de cuentas permitiendo que las instituciones externas al aparato gubernamental tengan acceso a los datos y se abra así la posibilidad de analizarlos (Schedler et al., 2004). Dicha apertura debe construirse con una secuencia de objetivos. En primer lugar, debe incrementarse el acceso a la información; posteriormente, asegurarse que las reglas sean transparentes y que se apliquen en la toma de decisiones, y finalmente que se construya la habilidad para rastrear las acciones y decisiones de los servidores públicos. En la medida en que dichos objetivos se persigan al mismo tiempo, la corrupción podrá reducirse de manera significativa (Subhash, 2003: 2).

Los programas de gobierno electrónico deben generar apertura per se, la cual va encaminada a mejorar el servicio gubernamental. "En términos generales, gobierno electrónico es concebido como una herramienta para el logro de los principios asociados al buen gobierno, entre los que destacan una gestión transparente y responsable” (Güémez, 2003: 33-34).

\subsection{Gobierno electrónico en México}

Los primeros pasos que dio México en materia de gobierno electrónico fueron durante la administración de Ernesto Zedillo (1994-2000). Durante ese periodo, diversos países de América Latina, como Argentina, Chile y Brasil, ya habían utilizado las TIC para la prestación de servicios públicos. México, ante la presión que ejerce la globalización, decidió entrar a esa corriente como parte del programa de reformas administrativas y regulatorias de la Organización para la Cooperación y el Desarrollo Económicos (OCDE). El desarrollo de un sistema de gobierno electrónico durante la administración de Zedillo se fue dando tanto con 
dificultades como con una clara descoordinación entre dependencias, las cuales establecían estrategias de forma independiente.

No obstante las dificultades que se vivieron durante el surgimiento de los primeros sistemas de gobierno electrónico en México, para el año de 1998, por ejemplo, el Sistema de Administración Tributaria (SAT) había logrado establecer una página de Internet interactiva en donde los contribuyentes y la población en general podían tener acceso a las leyes y regulaciones tributarias, así como realizar operaciones de forma electrónica. Ello constituyó un gran avance y la culminación del esfuerzo del gobierno en turno por introducir a México en la corriente mundial de gobierno electrónico, aunque claramente faltaba mucho por hacer.

El boom del gobierno electrónico en México se dio con la llegada de Vicente Fox a la presidencia de la República en el año 2000. Fox había "basado parcialmente su campaña en la promesa de seguir perfeccionando la calidad y eficiencia de los servicios gubernamentales y, fundamentalmente, de transformar la relación ciudadano-gobierno" (Kossic, 2003b: 3-4). En este sentido se creó el Sistema Nacional e-México, precisamente con el afán de desarrollar un gobierno menos corrupto y más cercano a las necesidades y demandas del pueblo. ${ }^{3}$

La introducción del gobierno electrónico por medio del Sistema Nacional e-México se estructuró de manera vertical, en donde el Consejo depende directamente de la presidencia de la República. Debajo de éste se encuentra la Secretaría de Comunicaciones y Transportes (SCT), encargada del desarrollo técnico del programa. Concretamente, desde el año 2003 la promoción e instrumentación de estrategias para el desarrollo del gobierno electrónico es responsabilidad de la Dirección General de Gobierno Electrónico, la cual radica en la Secretaría de la Función Pública. ${ }^{4}$

Las dificultades a las que se enfrentó el gobierno de Fox fueron las propias de la introducción de un nuevo sistema que se contrapone a prácticas arraigadas en la prestación de servicios públicos. La burocracia que se vive día con día en las dependen-

${ }^{3}$ El Sistema Nacional e-México, como proyecto presidencial, es el proyecto de Sociedad de la Información para México que opera desde la Secretaría de Comunicaciones y Transportes (sCT), http://www.e-mexico.gob.mx.

${ }^{4}$ La Dirección General de Gobierno Electrónico, dirigida por Abraham Sotelo, instrumenta iniciativas vinculadas con la Oficina de la Presidencia para la Innovación Gubernamental (a cargo de Ramón Muñoz), la cual ha tenido un papel protagónico en la modernización de Estado en general y del gobierno electrónico en particular. 
cias gubernamentales responde a un sistema anticuado de papeleo excesivo y largas filas para la realización de trámites comunes.

Uno de los objetivos principales de establecer un sistema de gobierno electrónico es precisamente agilizar los trámites y garantizar una prestación de servicios públicos eficiente. El esfuerzo de la administración de Fox ha logrado hasta el momento perfeccionar el e-SAT, facilitando con ello a contribuyentes cualquier trámite en materia de declaración de impuestos, esto por medio del portal Declaranet. Otro gran avance fue el desarrollo del portal Tramitanet, el cual "consiste de un catálogo en línea de aproximadamente 2,064 trámites federales y estatales” (Kossic, 2003a: 4); con ese portal se pretende hacer más eficientes los trámites al reducirse la burocracia.

Es evidente que toda implantación de gobierno electrónico exige transparentar el accionar del gobierno. En este sentido, durante el gobierno de Fox el portal de las secretarías ha vivido una verdadera transformación. Todas están vinculadas desde la página electrónica del gobierno y están interrelacionadas entre sí. ${ }^{5}$ Es decir, continuamente se hace referencia y se proporcionan vínculos a los portales de otras secretarías según la información que se busque.

\subsection{Gobierno electrónico en los estados}

Por medio del programa público e-local, se realiza un gran esfuerzo para conjuntar en un solo portal información relativa a los estados y municipios de la República Mexicana. ${ }^{6}$ El encargado directo de esa tarea es el Instituto Nacional para el Federalismo y el Desarrollo Municipal (INAFED), órgano desconcentrado de la Secretaría de Gobernación. Su función principal es “orientar y dirigir las políticas en materia de federalismo, descentralización, desarrollo municipal y descentralización del gobierno federal hacia los estados y los municipios" (Caballero, 2003: 3). Dicho portal contiene documentos, publicaciones e información estadística en general. Así pues, e-local funciona en realidad como un portal informativo y es, a su vez, un vínculo hacia las páginas electrónicas de cada uno de los estados, donde son éstos los responsables directos de la información que presentan y de los servicios que brindan. Lo anterior se refleja en una clara heteroge-

\footnotetext{
5 Disponible en http://www.gob.mx.

${ }^{6}$ Disponible en http://www.e-local.gob.mx.
} 
neidad en los servicios electrónicos de cada una de las entidades federativas. El esfuerzo que le corresponde al INAFED no consiste en unificar en los sistemas de gobierno electrónico, ni mucho menos en unificar los métodos estatales de rendición de cuentas y transparencia. Intentarlo sería ir en contra del esquema federalista mexicano. El reto del INAFED consiste en procurar que los sistemas de gobierno electrónico reflejen la separación de los niveles de gobierno, y que dentro de los portales estatales se brinde información de calidad y se responda a las necesidades de la ciudadanía.

Esa libertad de que gozan los estados para construir sus medios electrónicos de información y servicios públicos evidentemente ocasiona que se desarrollen portales a conveniencia del gobierno en turno. Desafortunadamente, en muchos de los casos éstos se convierten en meros sitios de publicidad turística. En suma, cada portal estatal presenta una interfase distinta que en ocasiones se caracteriza por el difícil acceso y la falta de información relevante.

\section{Transparencia en México en los ámbitos federal y estatal}

Los orígenes del concepto de transparencia se encuentran en la reforma constitucional de 1977, cuando se modificó la parte final del Artículo $6^{\circ}$ Constitucional introduciéndose la frase "el derecho a la información será garantizado por el Estado". Así, a lo largo de más de veinte años tanto la transparencia como los mecanismos de acceso a la información fueron abriéndose paso modestamente en la legislación mexicana, y no fue sino hasta el año 2000, con la consolidación de la democracia electoral, que esas ideas fueron consideradas en serio como un paso prioritario para que los ciudadanos pudieran evaluar la gestión del gobierno.

El acceso a la información por sí mismo no genera una ciudadanía más informada y responsable, pero crea el contexto necesario para que ésta pueda orientar mejor su acción política. Es decir, en un sistema político plural el acceso a la información es fundamental para que el ciudadano tenga la capacidad de hacer un juicio informado y fundamentado que le permita controlar a los poderes de la Unión por medio de su voto. Entonces, tanto la transparencia del gobierno como el acceso a la información pública son condiciones necesarias para el funcionamiento adecuado de los sistemas democráticos (López-Ayllón, 2005). 
Tal vez porque nacieron juntos, que no gemelos, el concepto de transparencia se relaciona con los mecanismos de acceso a la información. Sin embargo, el concepto de transparencia puede definirse como un instrumento cuyo propósito explícito es vigilar que las cosas ocurran según lo establecen las reglas del juego, a pesar de todas sus restricciones. También sirve como un instrumento y como un incentivo para recordarles a los funcionarios públicos que sus funciones solamente se justifican en la medida en que se correspondan con el interés público, que se atengan a las reglas del juego públicamente fijadas, y que rindan cuentas de las decisiones que toman a nombre de todos (Merino, 2005a: 17).

La publicación de la LTAIP constituyó un gran avance porque delimitó las obligaciones de transparencia del gobierno federal. Sin embargo, la vida jurídica de la transparencia reside en todos los servidores públicos en las diferentes entidades federativas. Desafortunadamente, la evaluación del avance de la legislación estatal no es alentadora: la apertura de la información no ha sido homogénea en todo el país. Merino (2005b), con base en el análisis de los documentos publicados por la Dirección General de Vinculación con Estados y Municipios del Instituto Federal de Acceso a la Información Pública (IFAI), bajo el título de Estudio comparativo de leyes de acceso a la información pública, así como en la revisión de las páginas electrónicas de los órganos estatales, concluye que no hay un criterio compartido por todas las entidades en materia de transparencia (Merino, 2005b: 74). Por ello la relevancia de cuestionarse hasta qué punto el gobierno electrónico ha afectado la transparencia de las finanzas públicas estatales como respuesta al cambio en el marco institucional generado por las nuevas LTAIP estatales.

\section{Marco teórico}

Para determinar si el gobierno electrónico genera cambios en la transparencia se aplicará el modelo teórico de presiones de la globalización y cambio burocrático (Wong y Welch, 1998 y 2001). La globalización trae consigo una serie de estímulos, desafíos y oportunidades en el contexto y características de las organizaciones que ejercen presión sobre las burocracias locales para generar cambios. Ejemplos de esas presiones de la globalización incluyen el arreglo institucional de acuerdos internacionales, la revolución de las TIC y la iniciativa de la reforma en la administración pública. En la medida en que las organizaciones públicas 
son sistemas abiertos que afectan y son afectados por su entorno, el conjunto de presiones globales puede generar cambios en la estructura y comportamiento de las burocracias públicas, incluyendo la transparencia de las mismas (Scott, 1998).

La cultura del gobierno electrónico es considerada como parte de la presión global de las TIC; sin embargo, aun frente a la presión de la globalización, la respuesta en cada burocracia no es necesariamente homogénea. Las presiones de la globalización afectan a las organizaciones públicas de acuerdo con el contexto local, de tal suerte que ese contexto puede reforzar o cancelar los cambios inducidos por las presiones globales sobre la burocracia (Wong y Welch, 2001).

La presión global de la revolución de las TIC apunta a un impacto directo y positivo del gobierno electrónico, en la transparencia. Sin embargo, también hay impactos indirectos en el contexto de las organizaciones que pueden reforzar o cancelar la influencia del gobierno electrónico en la transparencia. Entonces, es posible que el nivel de transparencia de un gobierno determinado disminuya debido a que el contexto cancela el impacto positivo y directo del gobierno electrónico.

En este caso, para cuantificar el impacto indirecto del contexto de las organizaciones, se considera el reciente cambio institucional generado en materia de transparencia en México a partir de 2002 con la publicación de la LTAIP. De hecho, ante los claroscuros que muestra el análisis de las leyes estatales de acceso a la información pública resulta pertinente preguntarse si los estados han encontrado en la adopción del gobierno electrónico una oportunidad para mejorar su transparencia. En principio, se esperaría una correlación positiva entre la presencia de la LTAIP estatal y la calidad de los reportes en línea de las finanzas públicas estatales. Si éste fuese el caso positivo, se verificaría que el gobierno electrónico utiliza las TIC para reproducir el cambio institucional generado en el entorno de las organizaciones locales.

Subhash (2003) argumenta que el simple acceso a tecnología no garantiza una mejor rendición de cuentas. Generalmente, los portales que se construyen son meras copias de los folletos gubernamentales impresos, lo que refuerza los sistemas antiguos en vez de constituir un esfuerzo notable para garantizar una mayor transparencia. ¿Cómo se podría explicar que, a pesar de la introducción de las TIC y del cambio que representan las LTAIP, los estados no hayan logrado mejorar la transparencia en sus finanzas públicas, necesaria para una mejor rendición de cuen- 
tas? Agre (2002) propone la utilización del modelo de reforzamiento para explicar justamente aquellos casos en los que el gobierno electrónico no genera cambios cualitativos importantes en las organizaciones. Así, se observa que la introducción de la Internet produce más de lo mismo que ya existía. La explicación de esa falta de cambios es atribuida a que las estructuras organizacionales permanecen literalmente inalteradas. En este caso, a pesar del cambio institucional que representa la LTAIP estatal, el gobierno electrónico reforzará el sistema de la organización, en vez de modificarlo (Agre, 2002). Es decir, los sistemas de gobierno electrónico instrumentados por los gobiernos estatales sólo estarían perpetuando el nivel de transparencia existente, en vez de alterarlo.

\section{Gobierno electrónico y transparencia en el reporte de las finanzas públicas estatales}

Un esquema federalista como el mexicano permite que sean los gobiernos subnacionales los responsables del manejo de sus finanzas públicas. Es decir, el federalismo fiscal es un sistema de gobierno que otorga diversas responsabilidades a los gobiernos estatales y locales, lo cuál "sugiere una división de funciones tanto de gasto como impositivas entre órdenes de gobierno basada en criterios relacionados con la eficiencia y la equidad" (Merino, 2001: 146). Entonces, al gozar de plena autonomía, son los gobiernos estatales los que determinan el contenido de los reportes de las finanzas públicas.

A partir del año 2002 y hasta el 2005, la mayoría de los estados publicaron su LTAIP. "Esto indica que existe un gran interés por parte de los gobiernos estatales en hacer más accesible la información que éstos generan, lo que es un buen principio para tratar de recuperar la confianza de los ciudadanos hacia los servidores públicos" (Gutiérrez, 2005: 7).

El objetivo de esta sección es analizar hasta qué punto el sistema de gobierno electrónico de cada estado ha mejorado la transparencia de las cifras de ingreso, gasto y deuda pública a partir del cambio institucional que generó la LTAIP estatal. ${ }^{7}$ Para ello,

${ }^{7}$ El Instituto Federal de Acceso a la Información Pública (IFAI) ha realizado evaluaciones a los sitios de Internet de dependencias de la Administración Pública Federal para determinar el grado de cumplimiento de cada una de ellas con las obligaciones de transparencia establecidas en la Ley Federal de Transparencia y Acceso a la Información Pública Gubernamental (LFTAIPG). En dichas evaluaciones se considera un apartado de 
primero se construirá un indicador del "Reporte mínimo esperado" de las cifras de ingreso, gasto y deuda de cada estado de acuerdo con lo que la LTAIP señala en cada caso. Posteriormente, se construirá una "Calificación Transparencia" que refleje tanto el desglose como la actualización de las cifras en cada una de las páginas Internet de los estados. Finalmente, se compararán ambas calificaciones para analizar hasta qué punto el gobierno electrónico, a partir de lo que establece la LTAIP estatal, ha contribuido a mejorar la transparencia de las finanzas públicas en los estados de México.

\subsection{Reporte mínimo esperado de acuerdo con la LTAIP estatal}

Para conocer lo que la LTAIP señala que cada estado debe publicar en cuanto a ingreso, gasto y deuda se utilizó el estudio de Gutiérrez (2005), quien analizó cuatro subcategorías de las finanzas públicas estatales: $i)$ presupuesto, ii) remuneración, iii) plazas disponibles, y iv) sistema de integración financiera. De las subcategorías mencionadas, la que más peso tiene es la de presupuesto, dentro de la cual se toma en cuenta lo que por ley se debe publicar en cuanto a estados financieros, cuenta pública y deuda pública. En esos rubros se encuentran las cifras de ingresos, egresos y deuda pública, objeto de análisis del presente trabajo. En el cuadro 1 se muestran, a partir de los resultados de Gutiérrez (2005), las obligaciones de cada estado. En la cuarta fila se ubica el Reporte mínimo esperado a partir de los rubros que la LTAIP marca como obligatorios. Allí, la letra "E" se refiere a excelente, la "S" a satisfactorio y la "M" a malo. Los nueve estados que no han aprobado su LTAIP (Baja California, Baja California Sur, Campeche, Chiapas, Chihuahua, Guerrero, Hidalgo, Oaxaca y Tabasco), automáticamente tienen un Reporte mínimo esperado malo (M). Al analizar el cuadro 1 se observa que el contenido de cada una de las LTAIP estatales en México es des-

estudio denominado "financiero", en el cual se verifica que en los portales se presenten cifras del gasto público, sueldos, subsidios y contrataciones. Así, "los resultados no reflejan toda la información disponible en los sitios de Internet, sino la proporción de las fracciones que incorporan efectivamente los conceptos que marcan efectivamente la Ley y su Reglamento. Para mayor detalle, consultar el comunicado del IfaI, México DF, 19 de mayo de 2004, http://www.ifai.org.mx/textos/gaceta/comunicado22190504.pdf. Este análisis difiere de los objetivos del presente trabajo porque verifica la existencia de los datos antes mencionados en los portales de las dependencias de la Administración Pública Federal y no de los gobiernos estatales. 


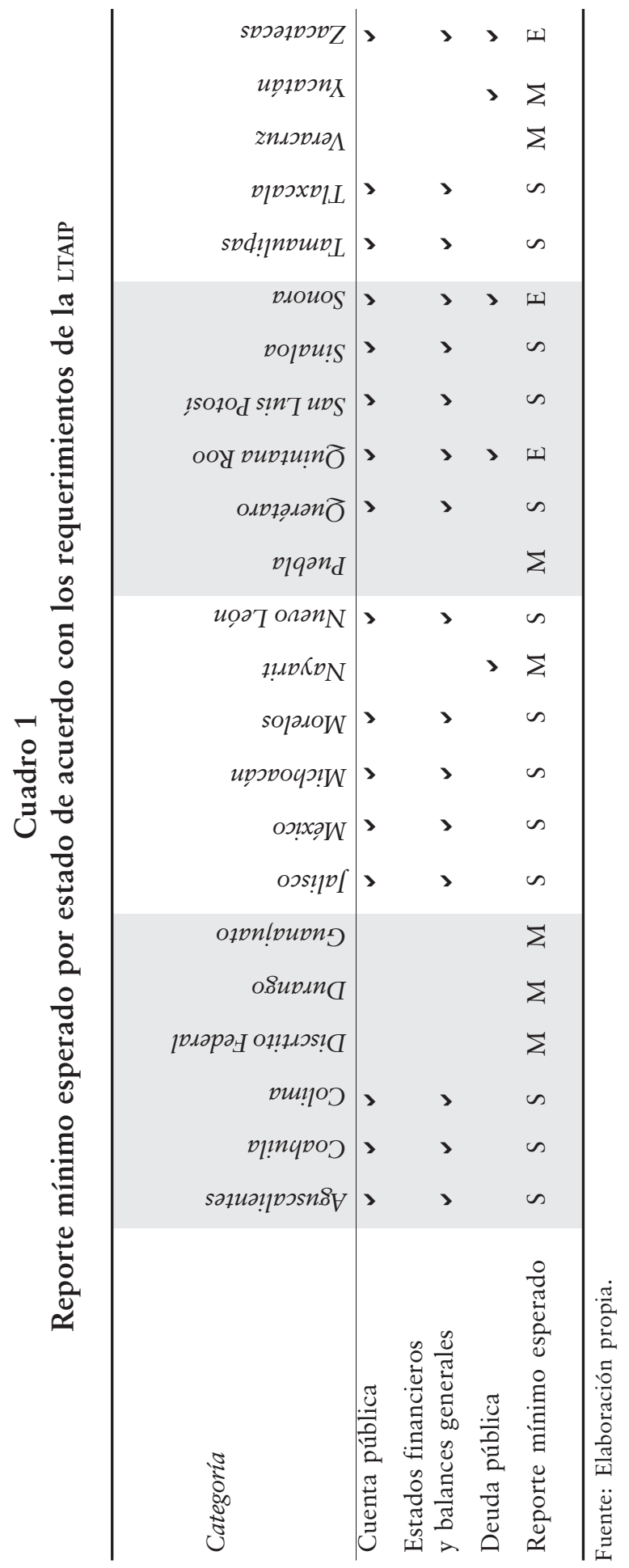


igual, lo que indica que las entidades federativas no comparten el mismo criterio de transparencia.

\subsection{Calificación transparencia estatal}

Debido a que la forma en que los estados reportan sus ingresos, egresos y saldos de deuda pública es muy variada, fue indispensable tomar en cuenta dos aspectos al momento de evaluar sus cifras publicadas en la Internet. El primero es el grado de desglose de los estados financieros, es decir, qué tan detallada se presenta la información. El segundo es el grado de actualización de las cifras, es decir, hasta qué año y trimestre tienen disponible su información en la Internet. ${ }^{8}$ Entonces, para evaluar el grado de desglose de las cifras, se estableció un mínimo de rubros de ingreso, gasto y deuda pública que deberían estar disponibles en los portales estatales. ${ }^{9}$ Por otra parte, en principio, los gobiernos estatales tienen la obligación de mantener sus cifras actualizadas hasta el último trimestre de su gestión. Por ello, para valorar esa actualización se consideró como mínimo la publicación de las cifras al menos del año inmediato anterior. ${ }^{10}$

Una vez calificados tanto el desglose como la actualización de las cifras de cada estado, se construyó la "Calificación transparencia”, misma que refleja la calificación más alta obtenida en cualquiera de esos aspectos. Por ejemplo, si el estado de Sinaloa obtuvo una calificación de desglose "Regular" y una de actualización "Satisfactoria", su calificación promedio será "Satisfactoria”. En el Cuadro 2 se analiza si existe correspondencia entre el Reporte mínimo esperado de acuerdo con la LTAIP y la Calificación transparencia obtenida por cada estado, a partir de las cifras que aparecen en sus páginas de Internet.

De los 23 estados que ya cuentan con una LTAIP, 39\% obtuvieron una Calificación transparencia mayor a su Reporte mínimo esperado; es decir, esas nueve entidades federativas publican sus cifras de finanzas públicas mejor de lo que su ley los obliga a hacerlo. Otros nueve estados obtuvieron una Calificación trans-

\footnotetext{
${ }^{8}$ En el Anexo 1 se encuentra un compendio de las páginas electrónicas estatales que fueron consultadas. Los datos en los que se basan los resultados aquí presentados fueron verificados al 5 de abril del 2005 .

${ }^{9}$ En los anexos 2, 3 y 4 aparecen los rubros que se consideraron para calificar el grado de desglose de la cifras de ingreso, gasto y deuda, respectivamente.

${ }^{10}$ En el Anexo 5 se presentan las calificaciones que cada estado obtuvo en el desglose y la actualización de sus cifras.
} 
Cuadro 2

Comparación entre Reporte mínimo esperado por la LTAIP y Calificación Transparencia para los estados que ya cuentan con una LTAIP (")

\begin{tabular}{lccl}
\hline \multicolumn{1}{c}{$\begin{array}{c}\text { Estados } \\
\text { con LTAIP }\end{array}$} & $\begin{array}{c}\text { Reporte } \\
\text { mínimo } \\
\text { esperado }\end{array}$ & $\begin{array}{c}\text { Calificación } \\
\text { Internet }\end{array}$ & Comparación \\
\hline Aguascalientes & $\mathrm{S}$ & $\mathrm{E}$ & Da un extra respecto a su ley \\
Coahuila & $\mathrm{S}$ & $\mathrm{B}$ & Da un extra respecto a su ley \\
Colima & $\mathrm{S}$ & $\mathrm{S}$ & Reporta según su ley \\
Distrito Federal & $\mathrm{M}$ & $\mathrm{S}$ & Da un extra respecto a su ley \\
Durango & $\mathrm{M}$ & $\mathrm{B}$ & Da un extra respecto a su ley \\
Guananjuato & $\mathrm{M}$ & $\mathrm{B}$ & Da un extra respecto a su ley \\
Jalisco & $\mathrm{S}$ & $\mathrm{R}$ & Reporta menos de lo esperado \\
México & $\mathrm{S}$ & $\mathrm{M}$ & Reporta menos de lo esperado \\
Michoacán & $\mathrm{S}$ & $\mathrm{S}$ & Reporta según su Ley \\
Morelos & $\mathrm{S}$ & $\mathrm{M}$ & Reporta menos de lo esperado \\
Nayarit & $\mathrm{M}$ & $\mathrm{M}$ & Reporta según su Ley \\
Nuevo León & $\mathrm{S}$ & $\mathrm{B}$ & Da un extra respecto a su ley \\
Puebla & $\mathrm{M}$ & $\mathrm{S}$ & Da un extra respecto a su ley \\
Querétaro & $\mathrm{S}$ & $\mathrm{R}$ & Reporta menos de lo esperado \\
Quintana Roo & $\mathrm{E}$ & $\mathrm{S}$ & Reporta menos de lo esperado \\
San Luis Potosí & $\mathrm{S}$ & $\mathrm{S}$ & Reporta según su Ley \\
Sinaloa & $\mathrm{S}$ & $\mathrm{S}$ & Reporta según su Ley \\
Sonora & $\mathrm{E}$ & $\mathrm{S}$ & Reporta menos de lo esperado \\
Tamaulipas & $\mathrm{S}$ & $\mathrm{M}$ & Reporta menos de lo esperado \\
Tlaxcala & $\mathrm{S}$ & $\mathrm{M}$ & Reporta menos de lo esperado \\
Veracruz & $\mathrm{M}$ & $\mathrm{S}$ & Da un extra respecto a su ley \\
Yucatán & $\mathrm{M}$ & $\mathrm{S}$ & Da un extra respecto a su ley \\
Zacatecas & $\mathrm{E}$ & $\mathrm{B}$ & Reporta menos de lo esperado \\
\hline & $\mathrm{S}$ & & \\
\hline
\end{tabular}

(*) La letra "E" se refiere a Excelente, "B" a Bueno, "S" a Satisfactorio, R" a Regular, y "M" a Malo.

Fuente: Elaboración propia. 
parencia igual al Reporte mínimo esperado; es decir, muestran una correspondencia entre lo que publican y lo que por ley están obligados a reportar. Sumando los casos donde la Calificación transparencia es mayor o igual al Repote mínimo esperado, podemos decir que en 78\% de los estados con una LTAIP se observa que el gobierno electrónico está reforzando el cambio institucional que representa la LTAIP en lo que se refiere a transparencia. En otras palabras, se comprueba que el gobierno electrónico está replicando el cambio institucional en el contexto de las organizaciones.

El resto de los estados (22\%) obtuvo una Calificación transparencia menor a su Reporte mínimo esperado. En esos casos no se encontró en las páginas electrónicas ni siquiera lo que por la LTAIP los estados están obligados a publicar. Se trata de cinco entidades federativas en donde las presiones que ejerce la introducción de una LTAIP, aunadas a las fuerzas de la globalización, no logran una correspondencia entre las características del contexto local y la transparencia observada. Habría que estudiar qué otro aspecto del contexto local puede estar ocasionado ese resultado. Como Wong y Welch (2004) señalan, pudiera tratarse de cuestiones organizacionales locales, como las características de la burocracia, las que pudieran explicar ese comportamiento.

En el Cuadro 3 se registran los nueve estados que no tienen una LTAIP, por lo que su Reporte mínimo esperado es malo. Se encuentra que cuatro de esos estados, al no contar con una LTAIP, obtienen una Calificación transparencia también mala. En esos casos, la aplicación del gobierno electrónico también está repitiendo el cambio en las características del contexto local: ante la ausencia de un cambio en el marco institucional, el nivel de transparencia es malo (véase cuadro 3).

Sorprendentemente, cinco de esas nueve entidades federativas tienen una Calificación transparencia mayor al Reporte mínimo esperado. Una posible explicación es que la burocracia local esté orientada hacia la transparencia y, aunque el cambio institucional de la LTAIP no se haya dado, se ha reforzado el efecto con la introducción del gobierno electrónico. ${ }^{11}$

${ }^{11}$ Cabe destacar que el análisis no califica la veracidad de las cifras, sino que se centra en comparar la evolución en términos de transparencia con base en el establecimiento de sistemas de gobierno electrónico. Futuros análisis en materia de reporte de finanzas públicas permitirán conocer la evolución de los gobiernos estatales en el fortalecimiento del federalismo fiscal y, a su vez, verificar si las TIC han sido aprovechadas para contribuir a la veracidad de las finanzas públicas estatales. 


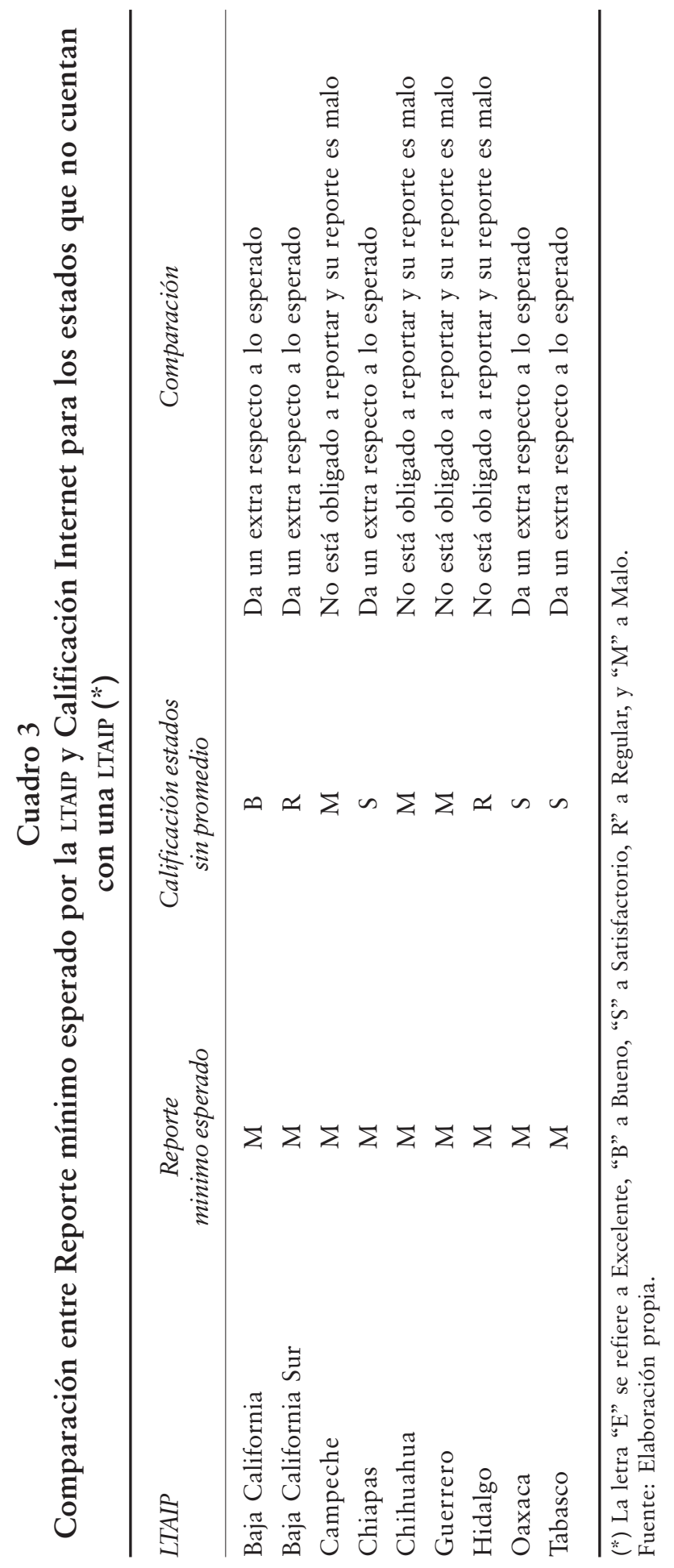




\section{Conclusiones}

La tecnología avanza día con día y ofrece mayores ventajas para la sociedad; y, en ese marco, el uso de la Internet ha revolucionado la forma de prestar servicios públicos. Así, los países transitan hacia la tecnificación de sus administraciones y hacen un uso cada vez mayor de las TIC. El aprovechamiento de la tecnología para la comunicación y el manejo de la información es lo que ha permitido crear sistemas como el del gobierno electrónico.

Los estados de la República tienen una ardua labor por delante. Un problema claro es que no todos están evolucionando al mismo ritmo ni en la introducción de sistemas locales de gobierno electrónico ni en la aprobación de sus respectivas LTAIP. Lo que sí es un hecho es que las LTAIP estatales crearon un nuevo marco institucional dentro del esquema de gobierno del país. El reto está en lograr amplificar dichas fuerzas con la adopción del gobierno electrónico. Específicamente, los portales deben servir como sitios de ampliación de la transparencia para una mejora de la rendición de cuentas que garantice gobiernos efectivos y comprometidos con el buen desempeño.

De acuerdo con la literatura de los efectos de la presión global de las TIC sobre el cambio burocrático, se encuentra que en 22 entidades federativas el gobierno electrónico amplia la naturaleza y características del contexto local de las organizaciones. Es decir, el efecto que se logra sobre la transparencia depende de las características del contexto local que rodea a las organizaciones. Ante el cambio institucional en el contexto local que representa la presencia o ausencia de la LTAIP, el sistema de gobierno electrónico reproduce ese elemento sobre el nivel de transparencia observado en las cifras de las finanzas públicas estatales. Entonces, la tecnología fue adoptada y luego adaptada para satisfacer las necesidades tanto institucionales como organizacionales de los estados.

Sin embargo, en cinco estados, aun ante la presencia de la LTAIP, no se observa el nivel de transparencia esperado. Es decir, hay algo en el contexto local que está cancelando el efecto directo de la presión que ejerce el gobierno electrónico, de forma que, a partir del análisis del reporte de las finanzas públicas estatales vía electrónica, se observan deficiencias en algunos estados en materia de desglose y actualización de sus cifras. Por otra parte, cinco estados presentan sus reportes de finanzas públicas de manera desglosada y actualizada incluso sin contar con una 
LTAIP. Para poder comprender a fondo que está pasando en ese $30 \%$ de los casos sería conveniente describir con más detalle el contexto local que rodea a las agencias encargadas de producir y publicar la información de las finanzas públicas en la Internet. Un posible camino es captar con más detalle las características de la burocracia a la que se le está pidiendo que adopte el sistema de gobierno electrónico.

Los logros alcanzados a la fecha con la introducción del gobierno electrónico no deben ser considerados como un logro final, sino como los primeros pasos hacia un país más transparente que permita una mejora en la rendición de cuentas, para así contribuir a la construcción de un mejor gobierno. La pronta solución a las deficiencias aquí presentadas, depende del compromiso que adquieran los gobiernos estatales en materia de transparencia y rendición de cuentas. Mientras no se amplifiquen los esquemas exitosos, los resultados estatales en materia de transparencia y rendición de cuentas no mejorarán.

\section{Bibliografía}

Agre, Philip E. (2002), "Real-Time Politics: The Internet and the Political Process", The Information Society, 18 (5), Los Ángeles, California, pp. 311-331.

Caballero, Vicente (2003), "Gobierno electrónico en la gestión estatal y municipal", Prospectiva: Temas de gobierno y administración pública, Agrupación Política Nueva, A.c., México, año 9, 25: 3-5.

Demchak, Chris C.; Christian Friis y Todd M. La Porte (2000), "Webbing Governance: National Differences in Constructing the Public Face”, en G. D. Garson (ed.), Handbook of Public Information Systems, Marcel Dekker Publisher, Nueva York.

Güémez, Ana María (2003), “Gobierno electrónico: ¿sinónimo de buen gobierno? Una aproximación a la luz de las experiencias internacionales y los esfuerzos de México", Prospectiva: Temas de gobierno y administración pública, Agrupación Política Nueva, A.c., México, año 9, 25: 33-40. 
Gutiérrez, Iñaki (2005), "Estudio comparativo de la información que debe publicarse de acuerdo a las leyes estatales y federal de transparencia”, AXITIA-Inteligencia en Internet, México.

Kossic, Robert M. (2003a), La transformación en la prestación de servicios gubernamentales en México: el caso del portal Tramitanet, Documento de Trabajo, núm. 141, División de Administración Pública (DAP)-Centro de Investigación y Docencia Económicas, México.

Kossic, Robert M. (2003b), Modernizing Mexico's Tax Administration: The Development, Implementation \& Impact of the e-SAT, División de Administración Pública (DAP), Centro de Investigación y Docencia Económicas, México (mimeo).

Kraemer, Kenneth y Jackson Dedrick (1997), “Computing and Public Organizations", Public Administration Research and Theory", 7: 89-112.

La Porte, Todd M.; Martin de Jong y Chris Demchack (2002), "Democracy and Bureaucracy in the Age of the Web", Administration and Society, 34: 411-426.

Lenihan, Donald G. (2002), E-Government, Federalism and Democracy: The New Governance, Toronto: Center for Collaborative Government, Toronto.

Ley Federal de Transparencia y Acceso a la Información Pública Gubernamental, en http://www.ifai.org.mx/transparencia/ LEY\%20FED\%20TRANSP\%20Y\%20ACC\%20A\%20 INF\%20PUB\%20GUB.pdf, 4 de octubre de 2005.

López, Ángel (2003), "En torno a las dificultades para arribar a e-Gobierno", Prospectiva: Temas de gobierno y administración pública, Agrupación Política Nueva, A.C., México, año 9, 25: 28-29.

López-Ayllón, Sergio (2005), "La creación de la Ley de Acceso a la Información en México: una perspectiva desde el Ejecutivo Federal" en Hugo A. Concha Cantú, Sergio López Ayllón, y Lucy Tacher Epelstein (coords.), Transparentar 
al Estado: la experiencia mexicana de acceso a la información, Instituto de Investigaciones Jurídicas, UNAM, México.

Merino, Gustavo (2001), "Federalismo fiscal: diagnóstico y propuestas”, en Una agenda para las finanzas públicas de México, Suplemento de Gaceta de Economía, ITAM, México, Cap. 4, pp. 145-185.

Merino, Mauricio (coord.) (2005a), Transparencia: libros, autores e ideas, CIDE- IFAI, México.

Merino, Mauricio (coord.) (2005b), "El desafio de la transparencia. Una revisión de las normas de acceso a la información pública en las entidades federativas de México", en Democracia y Transparencia, Instituto Electoral del Distrito Federal, Colección Sinergia núm. 5, México.

Scott, W. Richard (1998), Organizations: Rational, Natural and Open Systems, 4ª ed., Prentice Hall, Englewood Cliffs, NJ.

Schedler, Kuno; Lukas Summermatter y Bernhard Schmidt (2004), Managing the Electronic Government: From Vision to Practice, Information Age Publishing, Greenwich, Conn.

Subhash, Bhatnagar (2003), Administrative Corruption: How does E-Government help?, en http://www1.worldbank.org/publicsector/egov/Corruption $\% 20$ and $\% 20$ egov $\% 27 \mathrm{t} \%$ 20TI\%20Paper\%20Subhash.doc, 7 de noviembre de 2005.

Wong, Wilson y Eric Welch (1998), "Public Administration in a Global Context: Bridging the Gasps of Theory and Practice between Western and Non-Western Nations", Public Administration Review, 58: 40-49.

Wong, Wilson y Eric Welch (2001), “Effects of Global Pressures on Public Bureaucracy: Modeling a New Theoretical Framework", Administration and Society, 32: 371-402. 
Wong, Wilson y Eric Welch (2004), “Does E-Government Promote Accountability? A Comparative Analysis of Website Openness and Government Accountability", Governance: An International Journal of Policy, Administration, and Institutions, 17 (2): 275-297.

Recibido: 4 de octubre de 2005. Reenviado: 8 de febrero de 2006. Reenviado: 30 de mayo de 2006. Aceptado: 12 de junio de 2006.

Laura Sour-Vargas es doctora en políticas públicas por la Escuela Irving. B. Harris School de Políticas Públicas de la Universidad de Chicago, asimismo realizó sus estudios de Licenciatura y Maestría en Economía en el Instituto Tecnológico Autónomo de México (ITAM). Actualmente es investigadora nivel I en el Sistema Nacional de Investigadores (SNI) y es la Coordinadora Ejecutiva del Programa de Presupuesto y Gasto Público del Centro de Investigación y Docencia Económicas (CIDE). Sus líneas de investigación actuales son el presupuesto y gasto público, finanzas públicas, descentralización, cumplimiento del pago de impuestos y economía experimental. Entre sus publicaciones destacan: "Cumplimiento fiscal y bienes públicos ¿Son realmente compatibles?”, El Trimestre Económico, vol. 73, núm. 292, pp. 863880, octubre-diciembre, 2006; "El Sistema de Transferencias Federales en México: ¿Premio o castigo para el esfuerzo fiscal de los Gobiernos Locales urbanos?" Gestión y Política Pública, vol. XIII, núm. 3. 


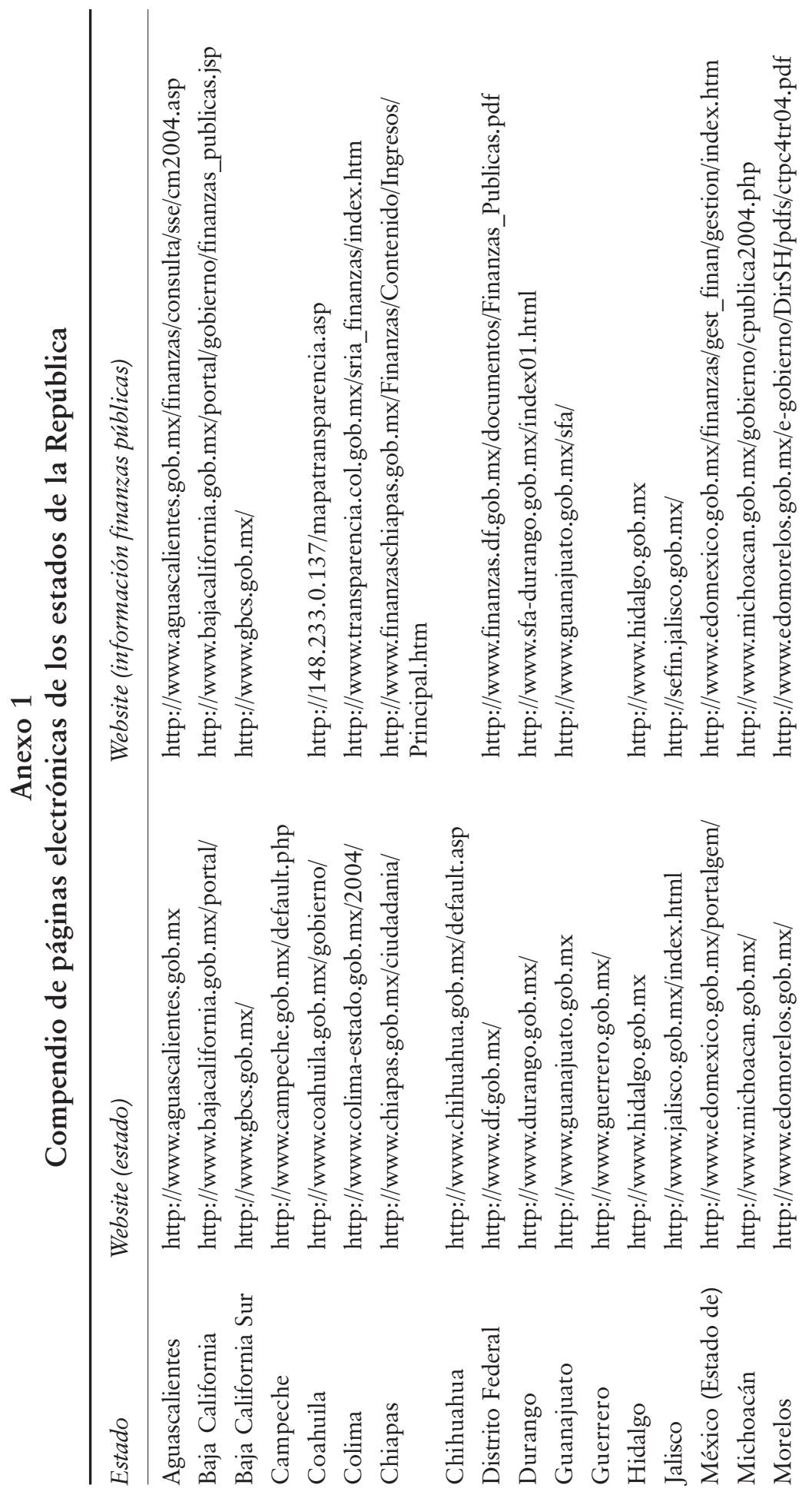




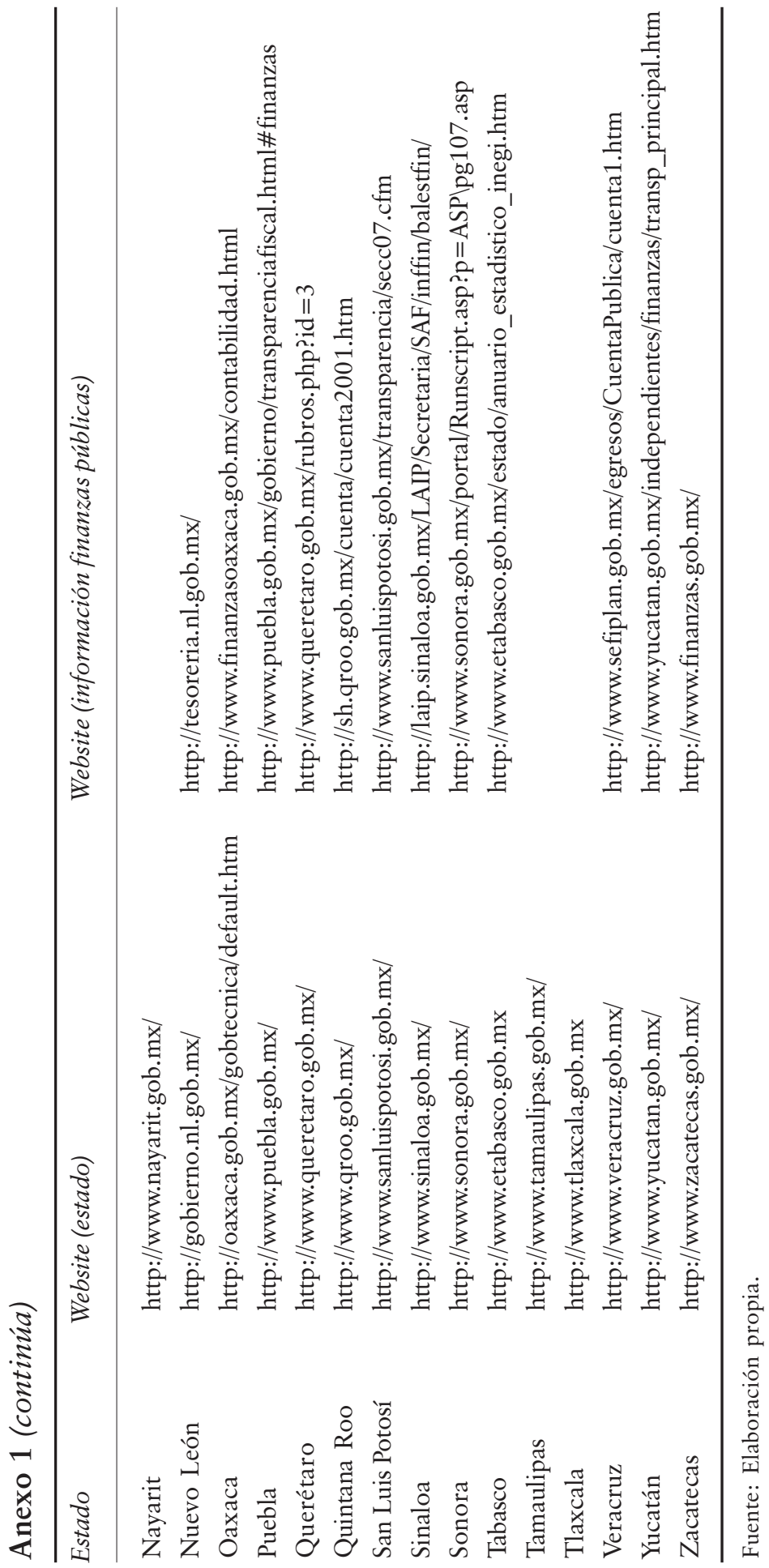




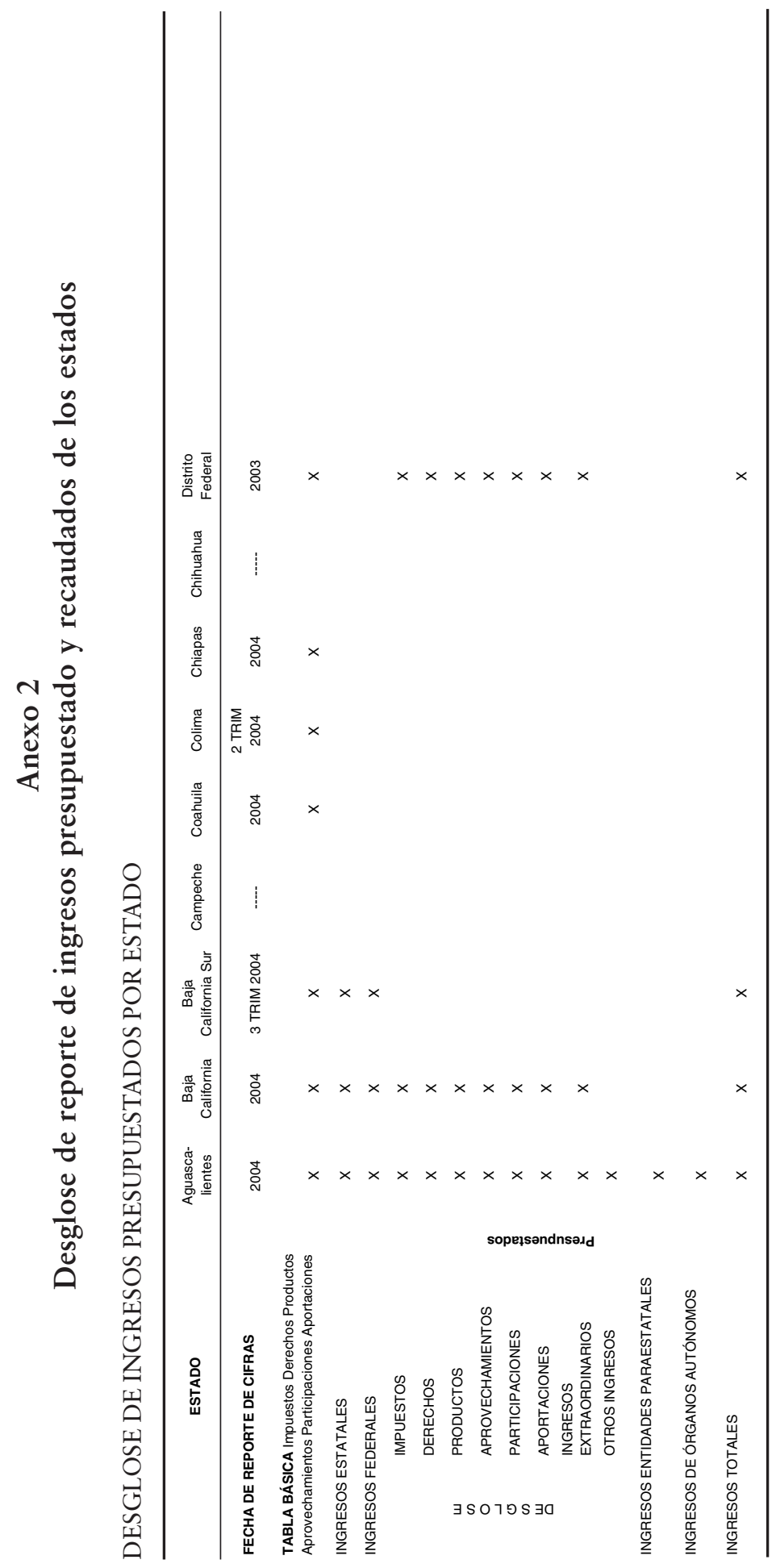




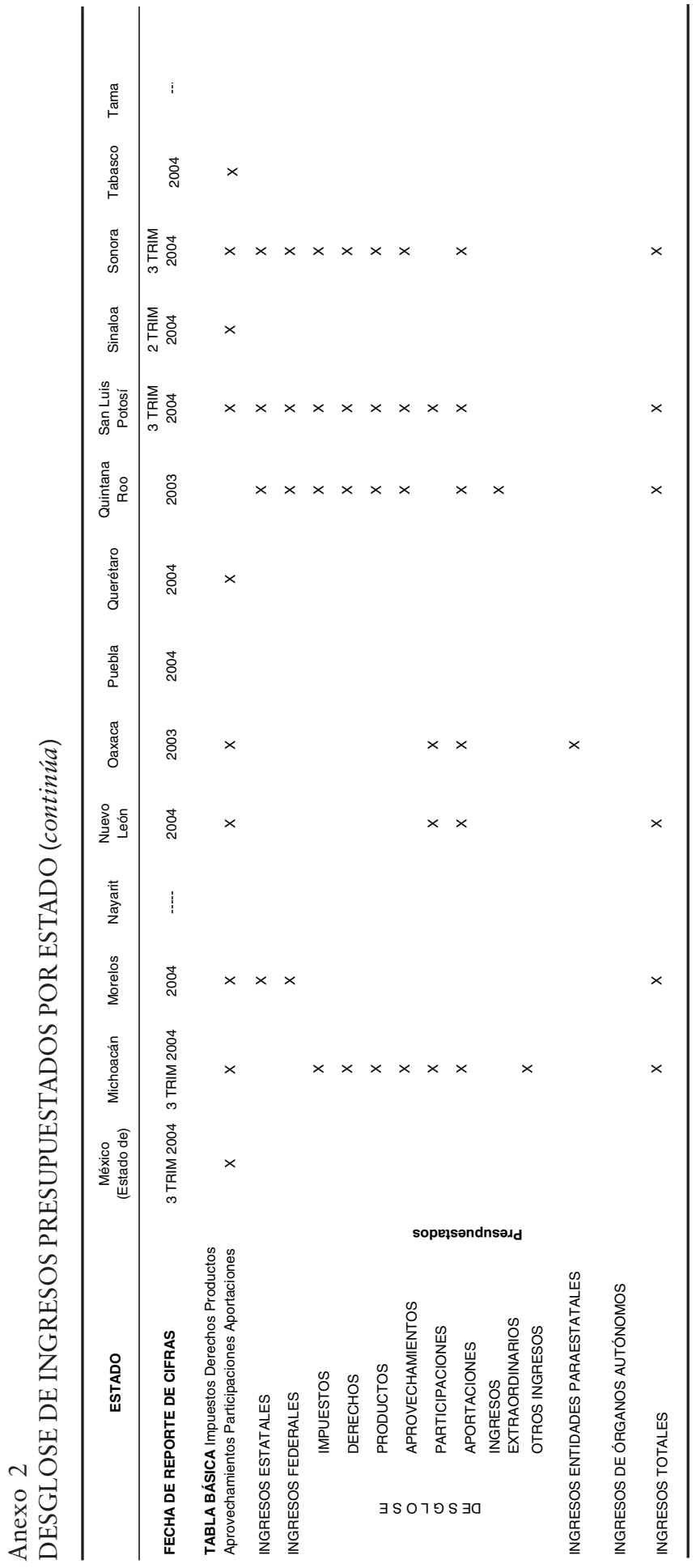




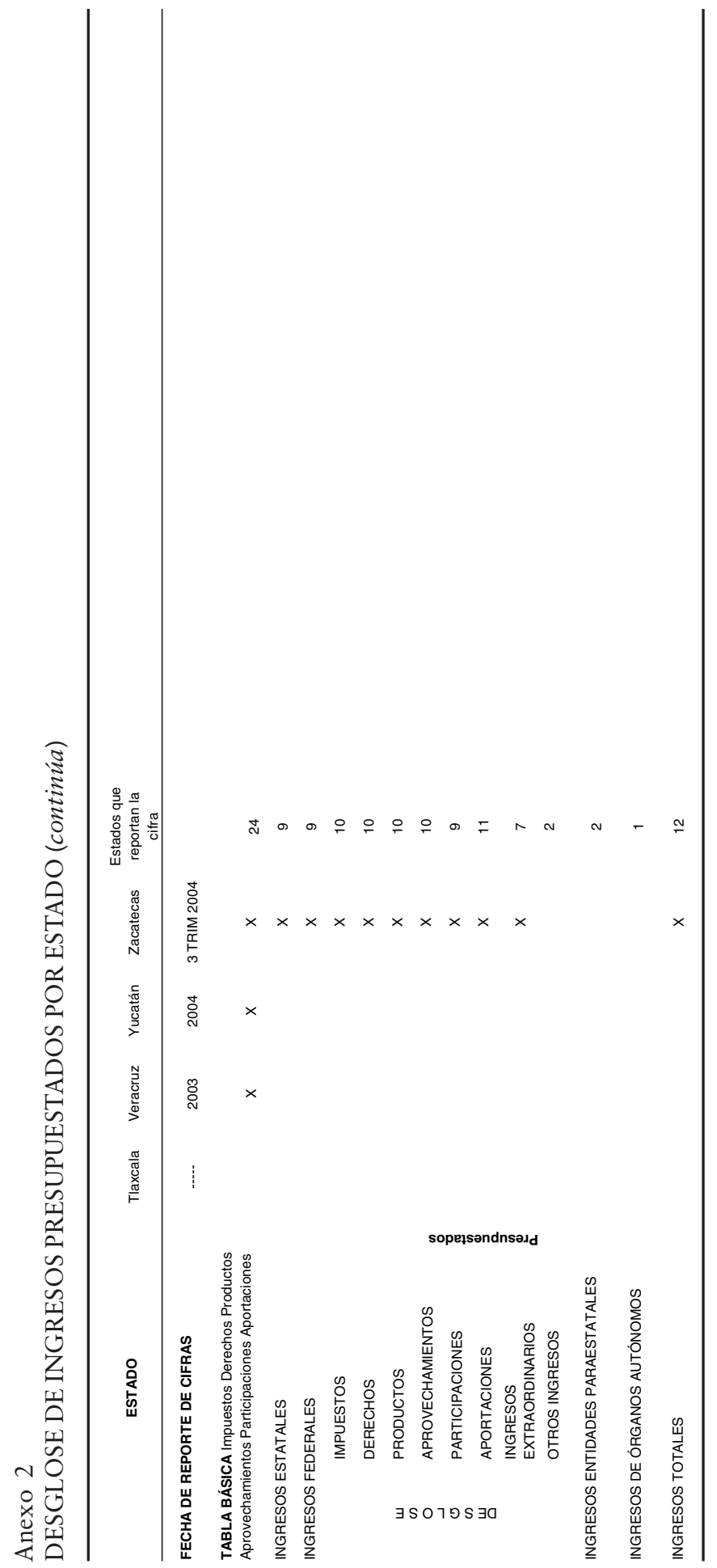




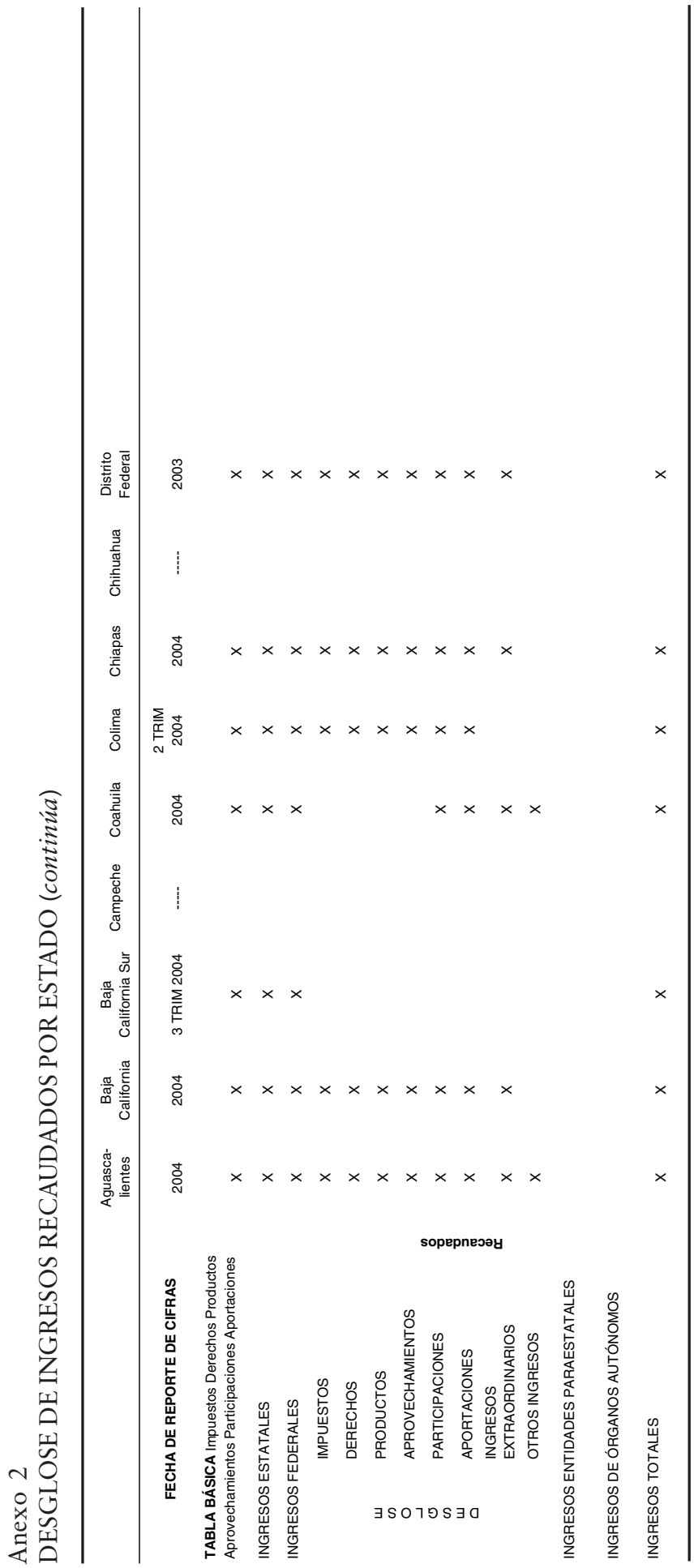




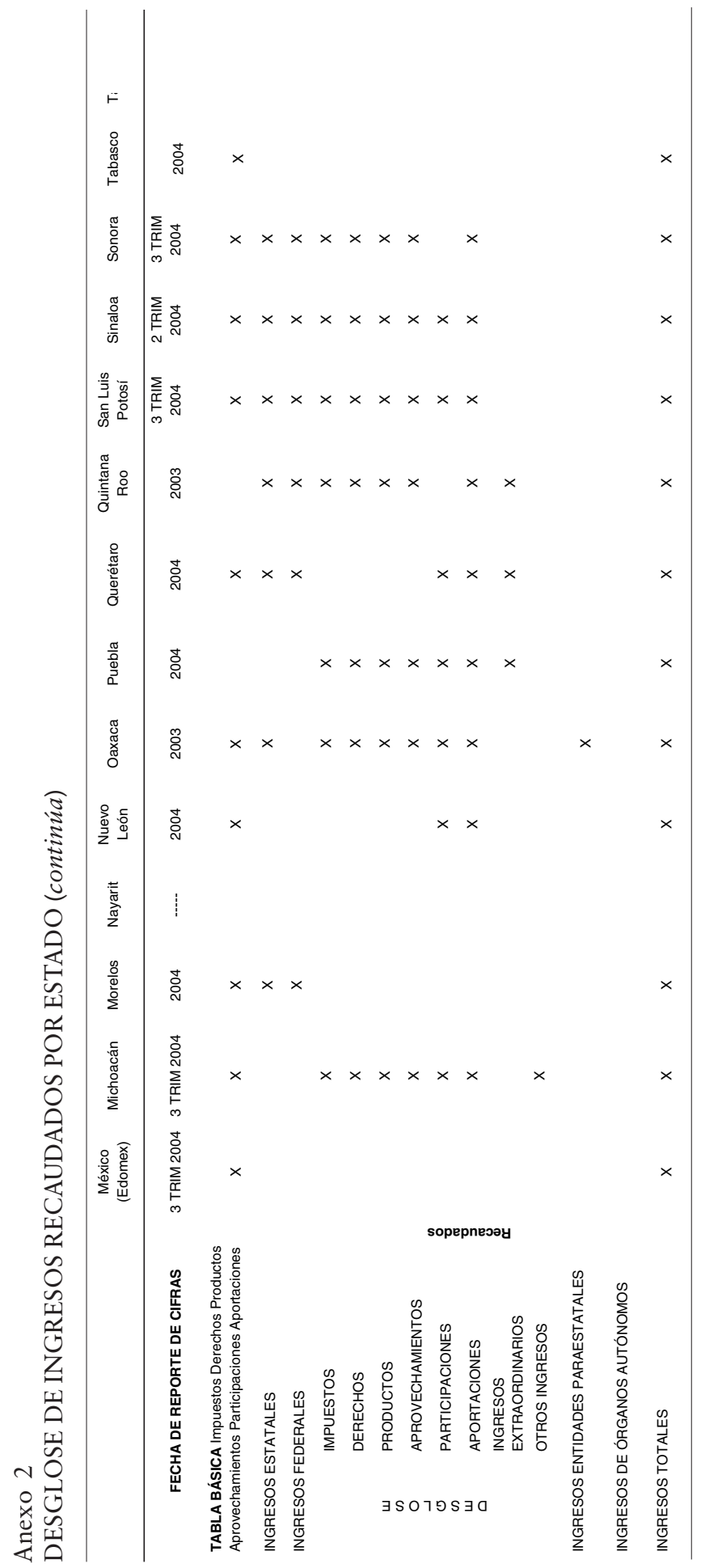




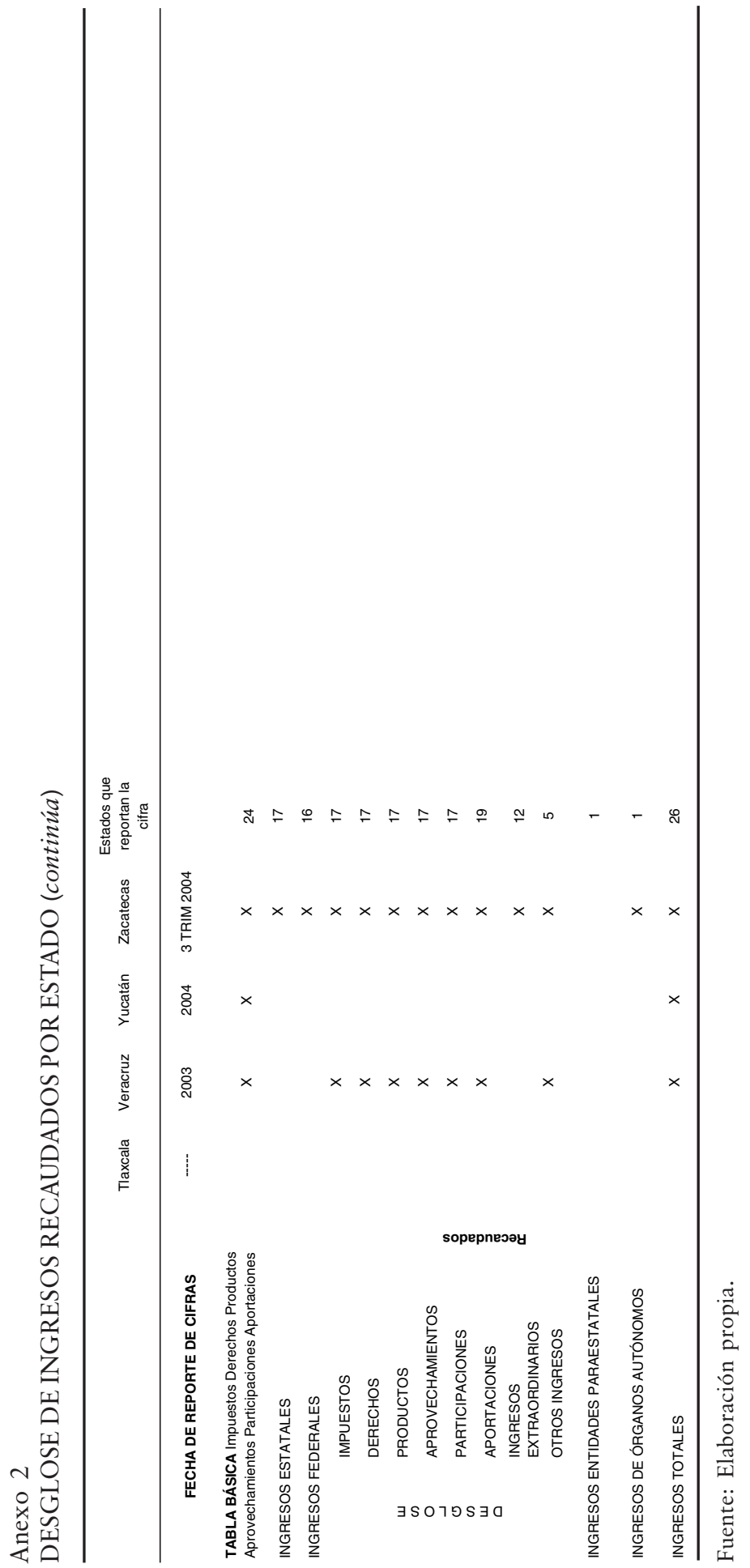




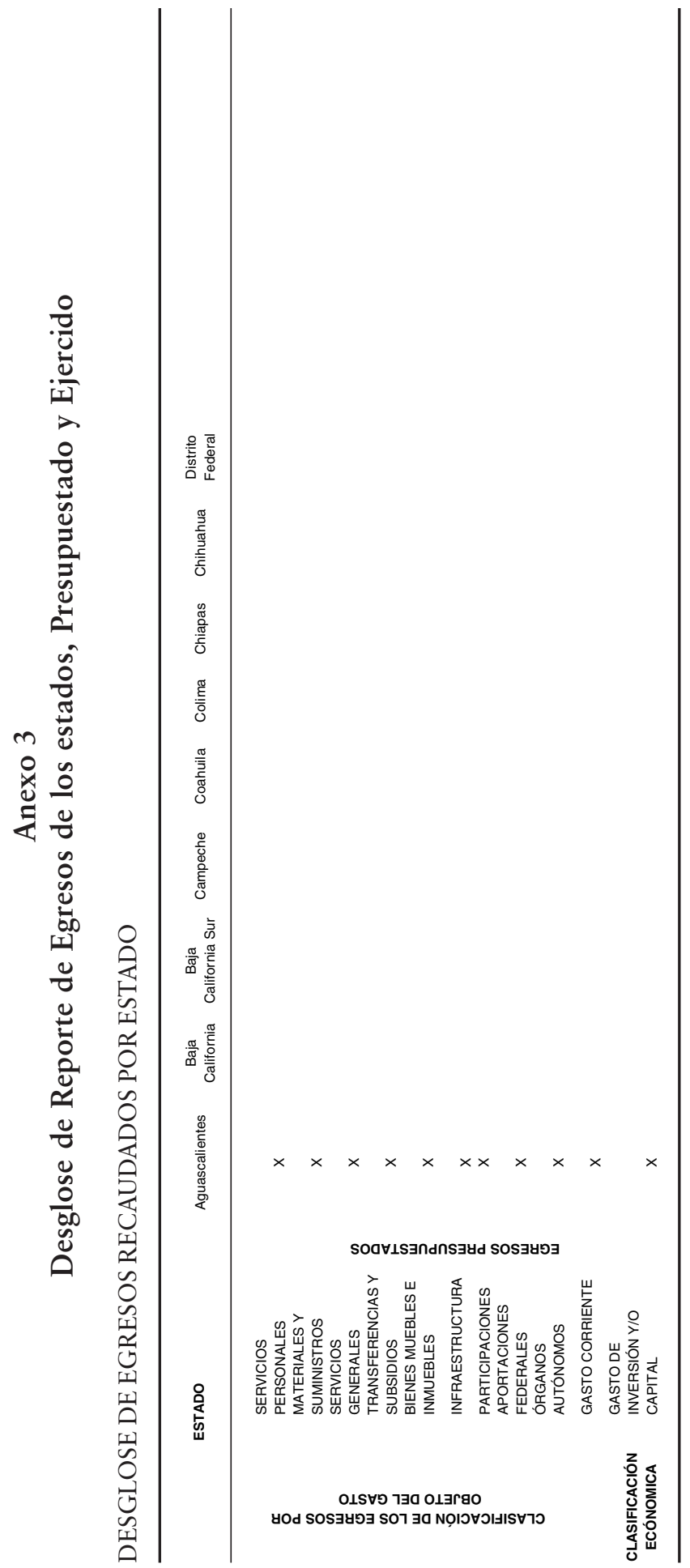




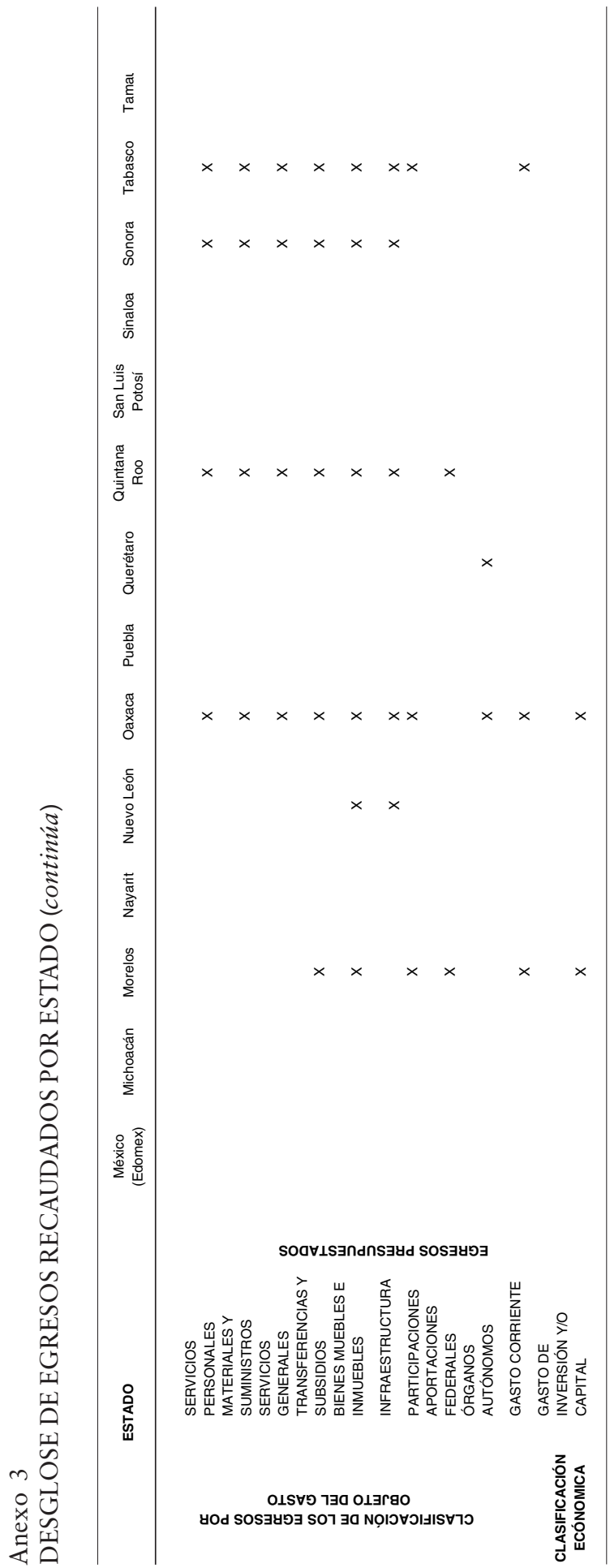




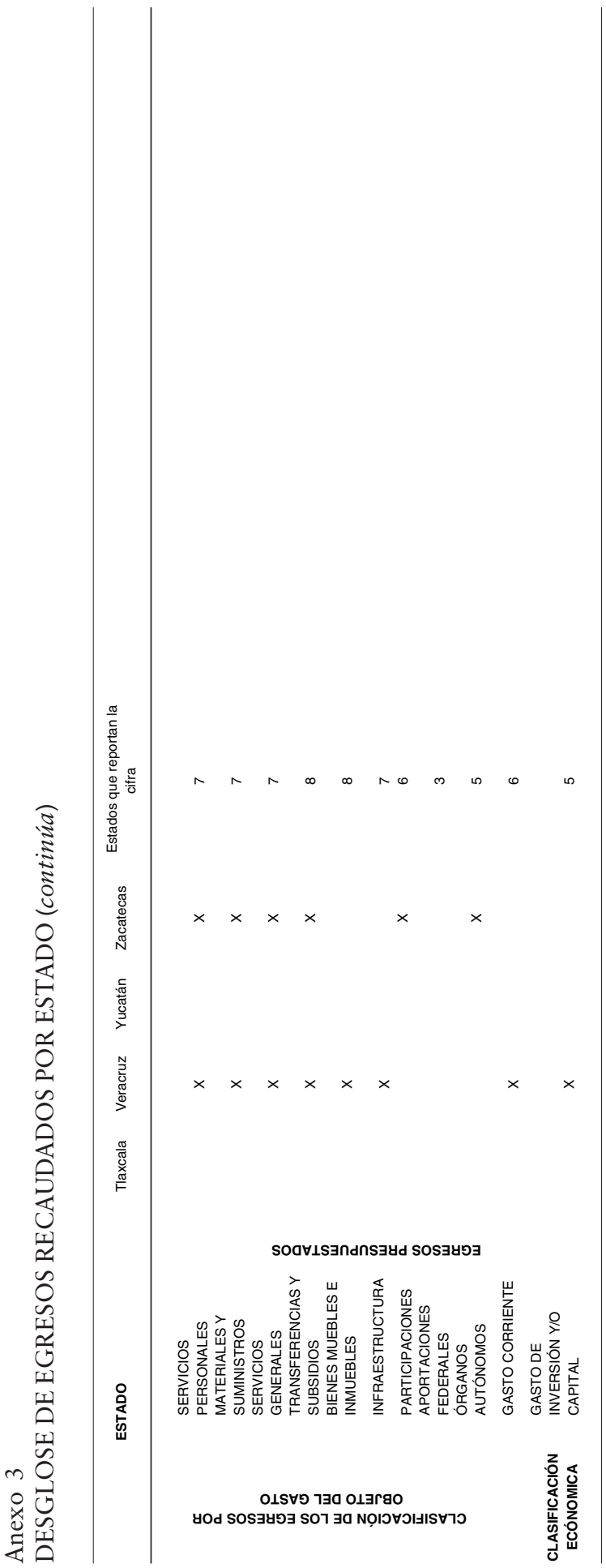




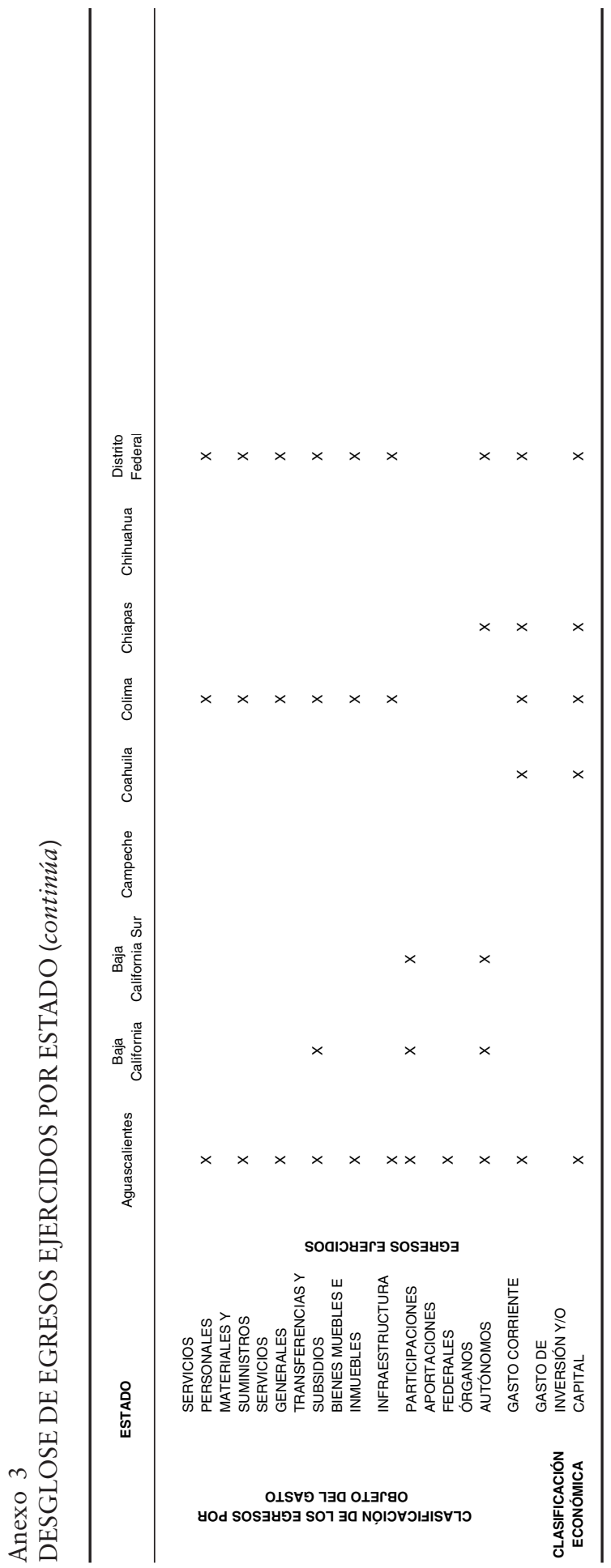




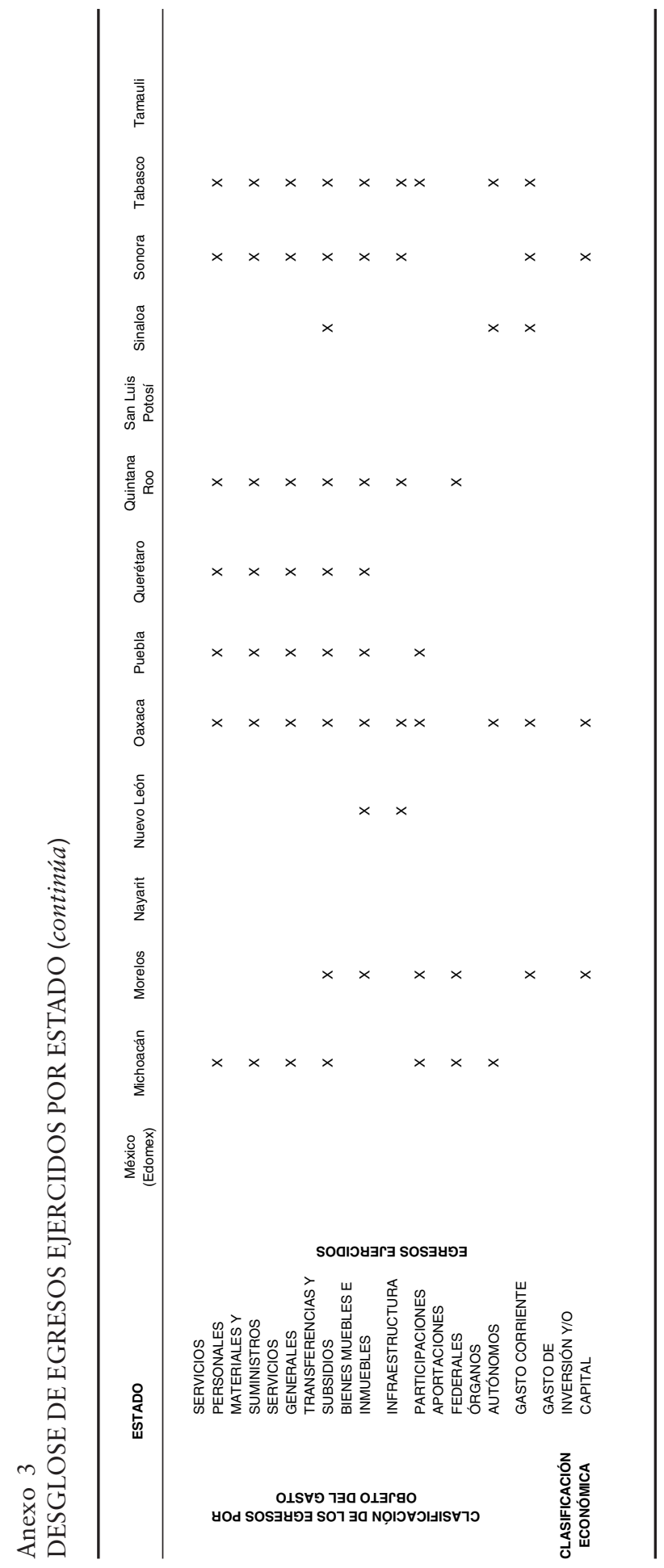




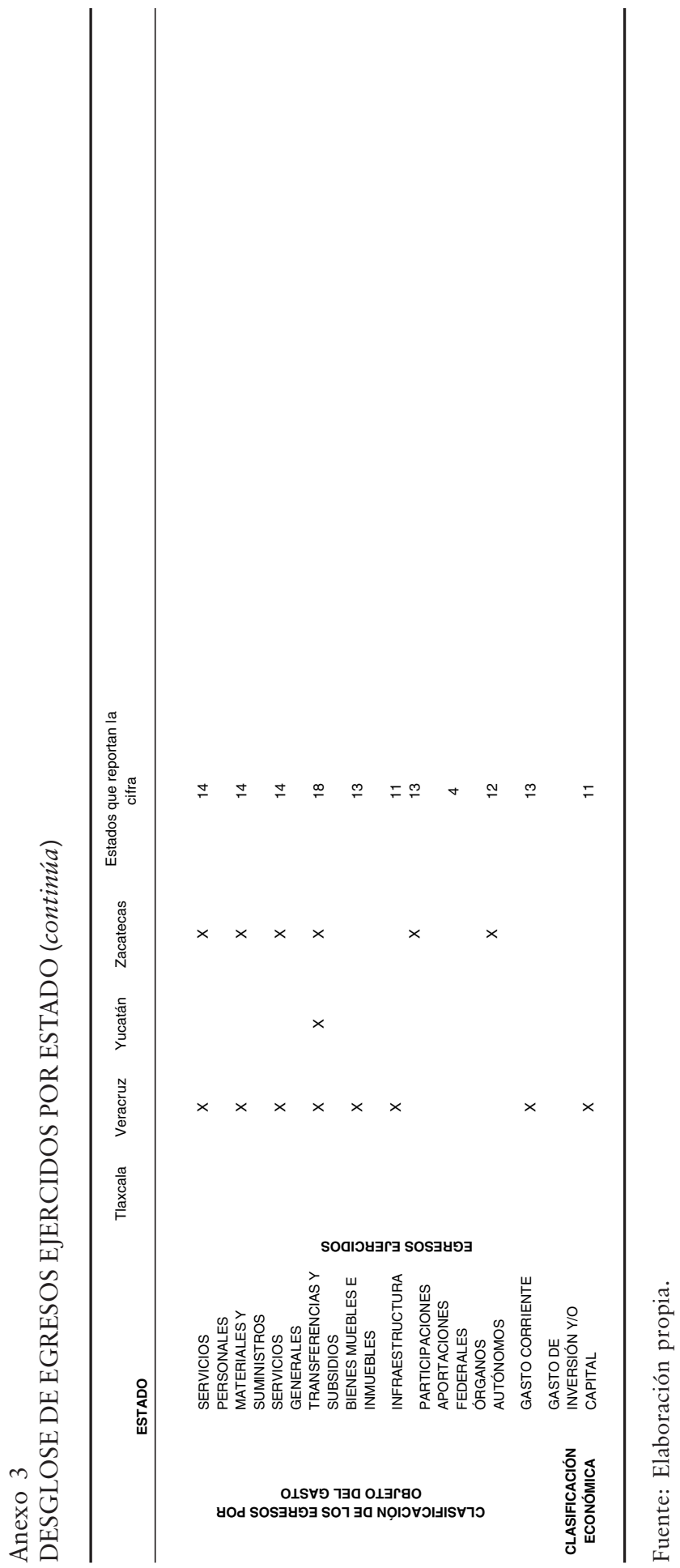




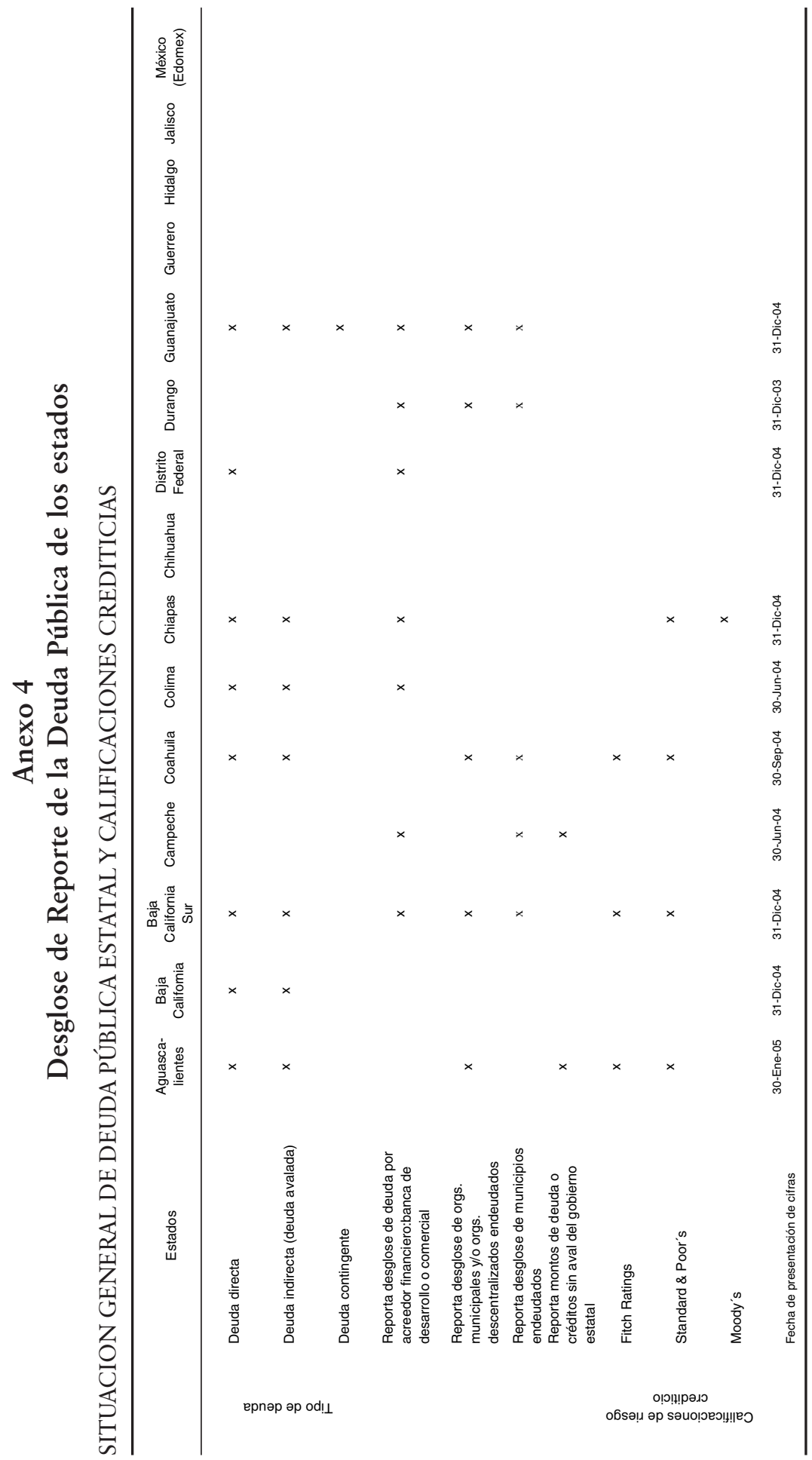




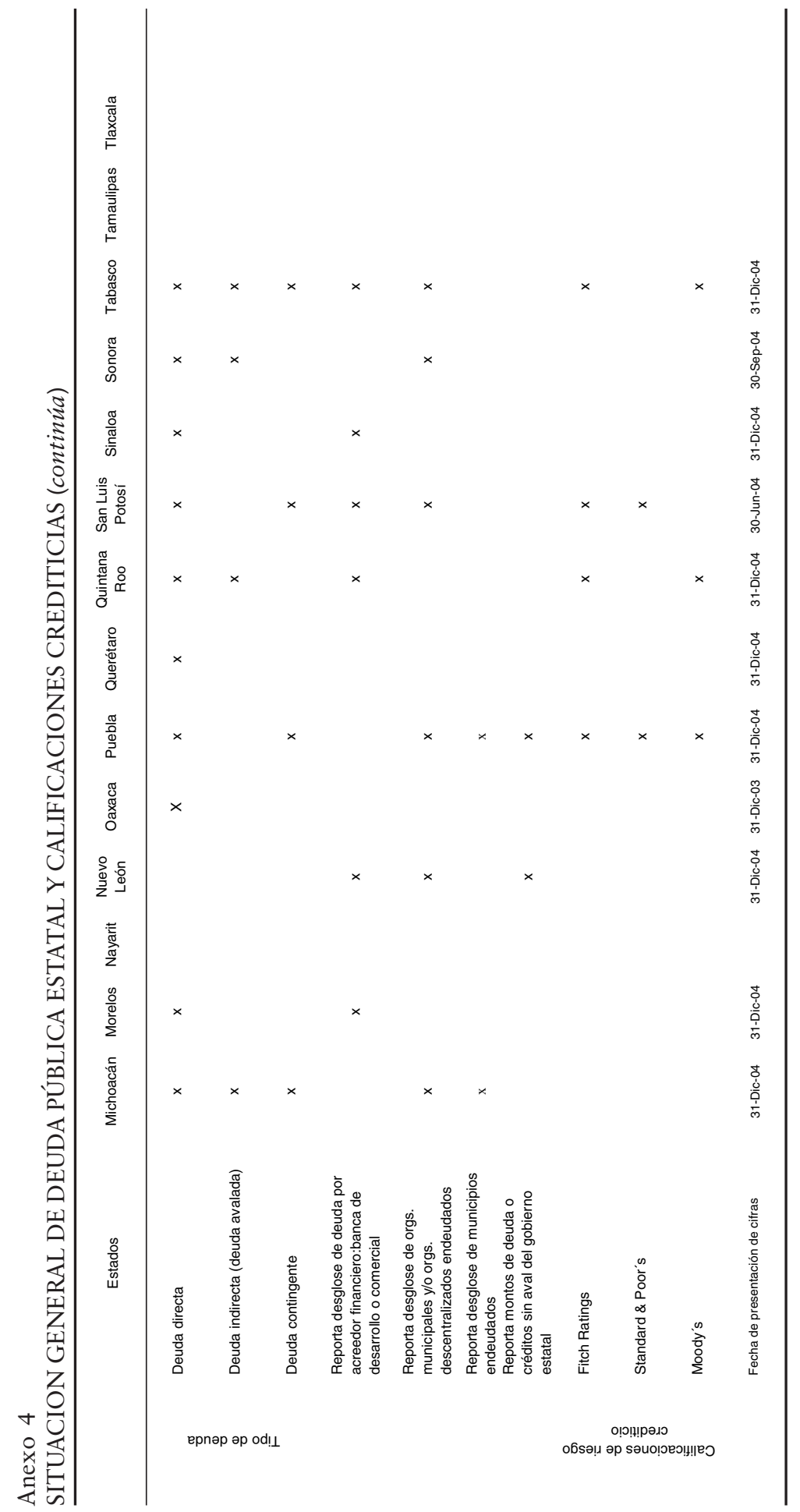




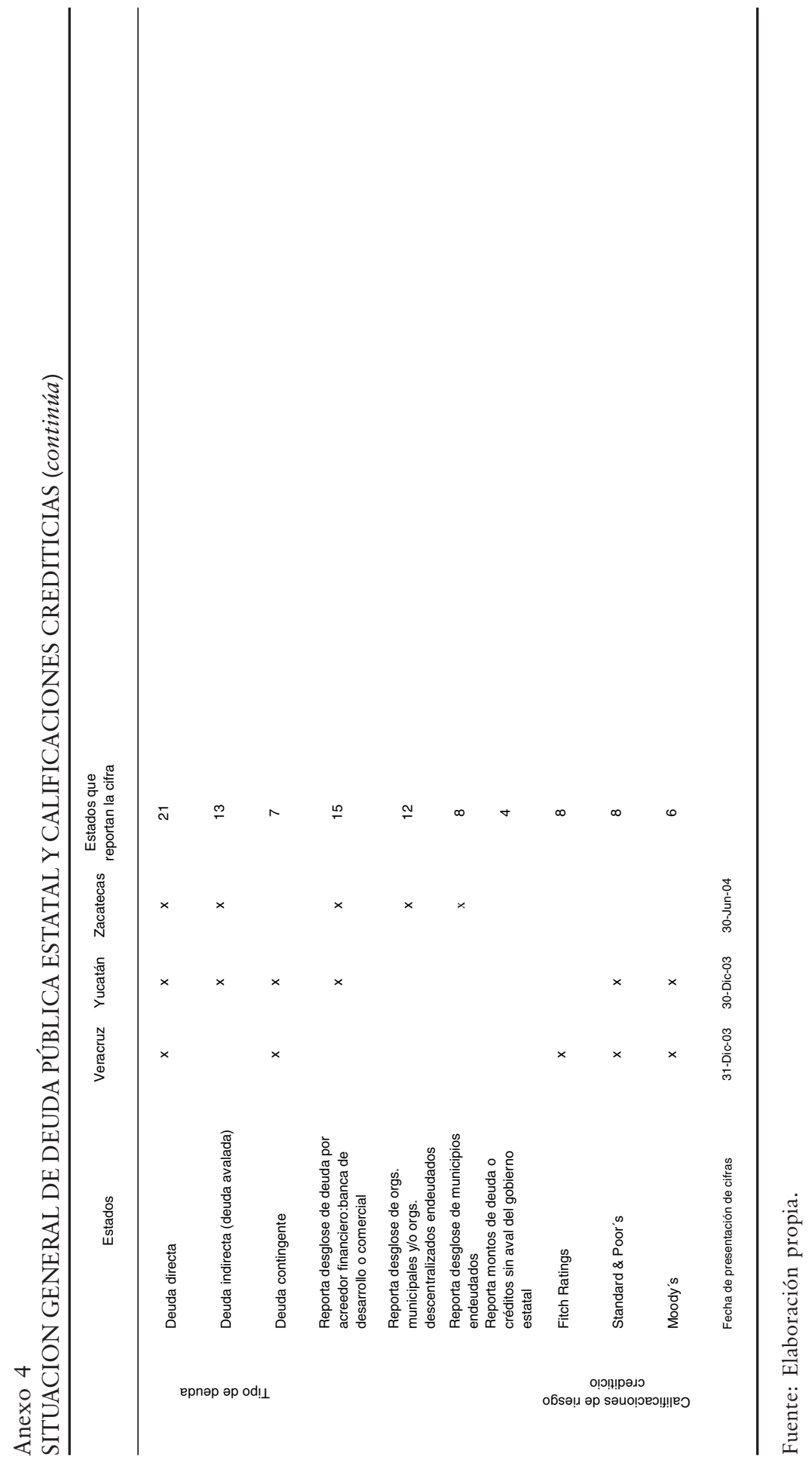




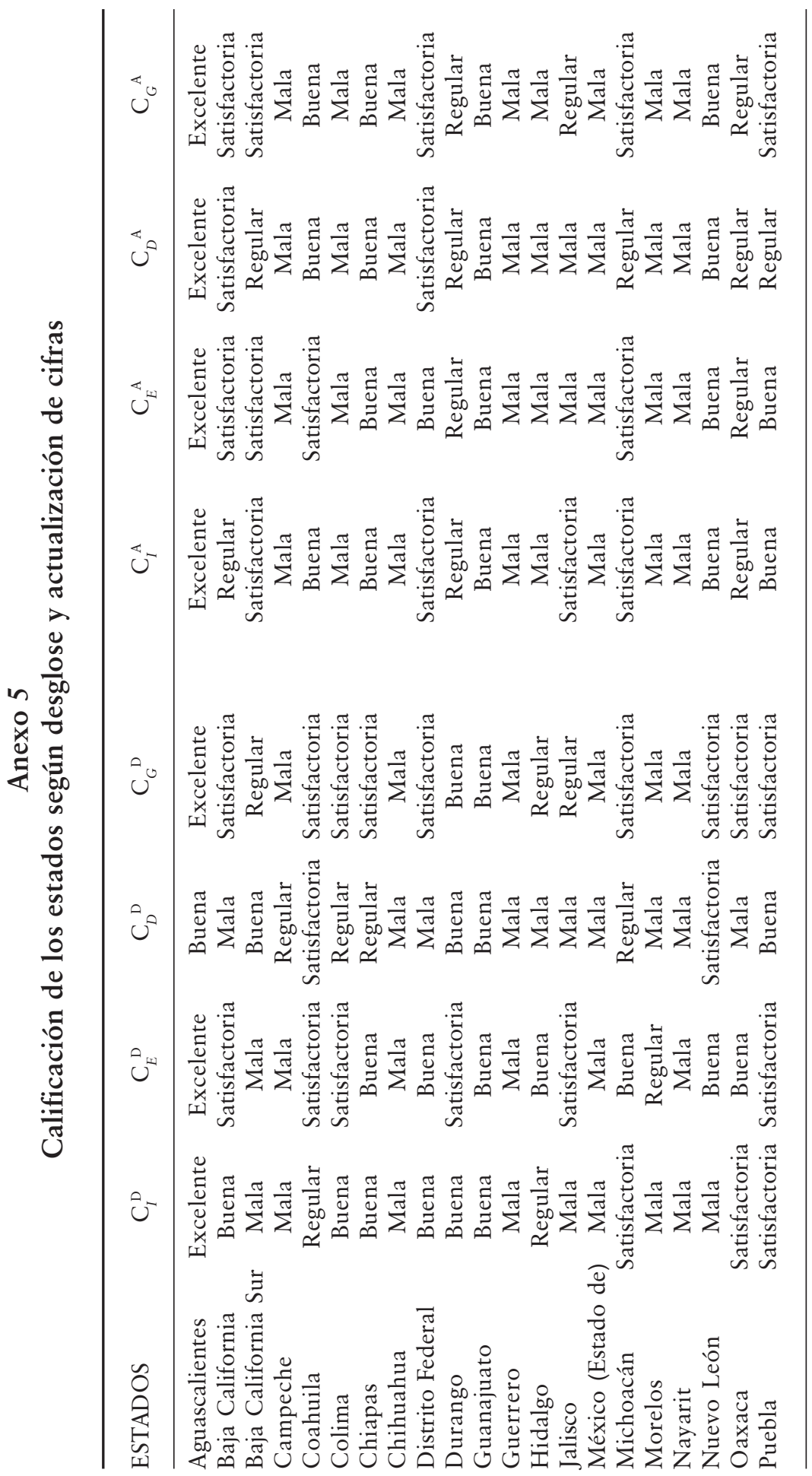




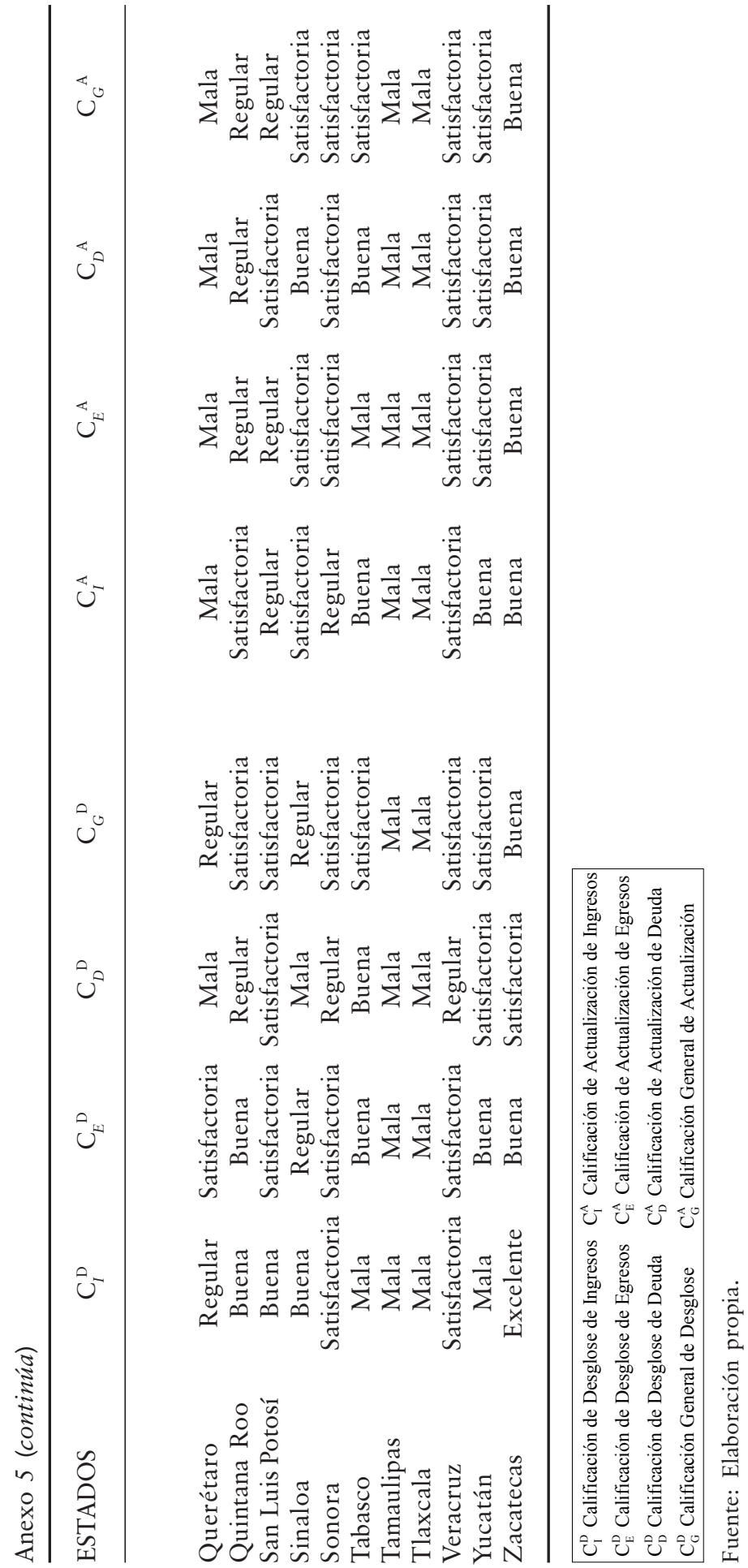

